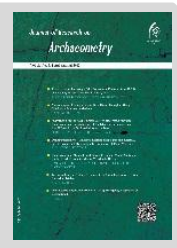

\title{
Detecting the location of unmarked graves for archaeological purposes using Ground-Penetrating Radar (GPR)
}

\author{
Reza Ahmadi* \\ ${ }^{1}$ Assistant Professor OF Mining Engineering Department, Arak University of Technology, Arak, IRAN
}

Received: 20/08/2019

Accepted: 04/11/2019

\begin{abstract}
Ground penetrating radar (GPR) is a non-destructive evaluation geophysical method that is able to detect and imaging the all kinds of human handmade structures, subsurface heterogeneities caused by buried objects, identifying empty spaces and cavities in environments and shallow buried targets. GPR has many applications in diverse fields of engineering and science. In the present research, the ability of employing GPR method to detect and determine the location of unmarked graves and buried corps, for archaeological purposes and similar cases has been investigated. In Iran country, the GPR method has not been widely used in archeology, especially for discovery of unmarked graves and detection of buried corps. In many areas of Iran, there are ancient cemeteries and historical tombs that require applying non-destructive and efficient geophysical methods such as GPR method in order for complete subsurface identification. To detect the exact location of unmarked graves and identification of underground human bodies by archaeogeophysical methods, having complete knowledge of the size of the human body's skeleton (bones), dimensions and material types of various coffins, mummy types and the effect of mummy on the permanence time of the body, decomposition of a corpse, procedure of body burial in different religions and burial depth of corpse is required. To achieve the goal, simulation and forward modeling of GPR data using 2D finite-different method improved in the frequency domain, has been carried out for synthetic models corresponding to empty graves, bones of human body's members as well as coffins with kinds of materials (wooden and metallic). The most of traditional coffins are wooden with the variety of designs and styles whereas relatively newer ones are made from metal. For this reason, these two types are used for modeling. In forward modeling of synthetic models, the central frequency of antenna was selected about $250 \mathrm{MHz}$ to $500 \mathrm{MHz}$. The host medium of targets was chosen from silty clay soil, dry sand and gravel or sandy soil. In order to avoid numerical dispersion, the spatial discretization intervals (grid dimensions) along the $\mathrm{X}$ and $\mathrm{Z}$ axes were determined equal to $0.01 \mathrm{~m}$. Also to prevent numerical instability, temporal sampling rate was set to $0.005 \mathrm{~ns}$. Since in reality, coffins are usually at depths of $1 \mathrm{ft}$ to $2 \mathrm{ft}$, in the simulations burial depth of upper surface of the coffin or corps was set to $0.8 \mathrm{~m}$ to $1.2 \mathrm{~m}$ and the overall depth of the grave was considered maximum $2 \mathrm{~m}$. According to the results of the forward modeling, regarding an empty grave, the response of the target top is as hyperbolic with a flat peak while for the bottom of the model is a defective hyperbolic with a flat peak. Therefore, in interpreting the results of actual GPR radargrams this type of response indicates the presence of a cubic structure like a buried grave. In general, the GPR response of the human's body represents itself as a hyperbolic reflection. For a buried target with a geometrical shape like a wooden coffin filled with air, the response of top and
\end{abstract}

*Corresponding author: rezahmadi@gmail.com 
bottom of the coffin is clearly distinguished and the reflection intensity off both responses is relatively strong. Regarding the metallic coffin the response of top is stronger than the wooden one but there is no reflection from its bottom that is due to the strong reflection off the metal and the high attenuation of the electromagnetic waves by the metals. Also in order to investigate the subsurface of the pretty old cemetery, real GPR data was acquired using a GPR system equipped with $800 \mathrm{MHz}$ central frequency shielded antenna. The finalized radargram along one of the surveyed profiles in the studied area through applying various sequence processing containing static correction, dewow filter, band-pass filter, background removal and stacking on the GPR raw data using Reflexw software has also been provided. The results of this research, on the basis of produced GPR responses for the variety of synthetic models and the radargram of real GPR data, show the capability of application of GPR method for archaeological investigations to detect and locate hidden graves, coffins and human corps by expending low cost in a short time without any manipulation and destruction of the environment.

Keywords: Archaeometry, Geophysics, Ground-penetrating radar (GPR), Forward modeling, Grave, Bone 


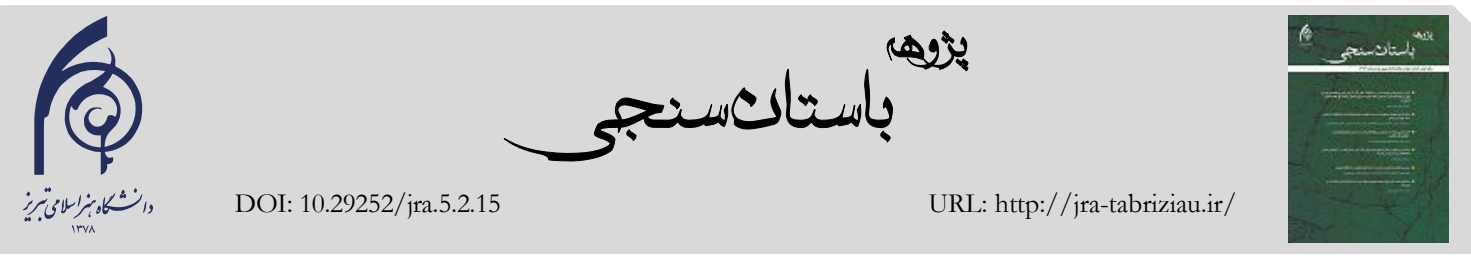

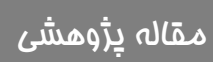

\section{Crosshark (GPR) رضا احمدى \\ استاديار گروه مهندسى معدن، دانشكده مهندسى علوم زمين، دانشخاه صنعتى اراك، اراك، ايران}

تاريخ يذيرش: سرم

تاريخ دريافت:

\section{جִكيده}

روش زئوفيزيكى رادار نفوذى به زمين (GPR) يكى روش سنجش غيرمخرب است كه قادر بــه آشكارسـازى و تصـويركردن انـواع

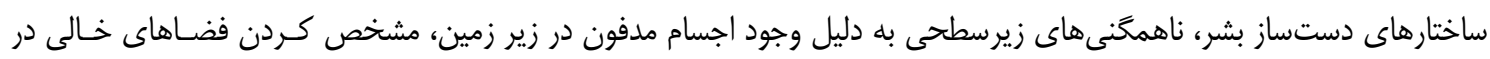

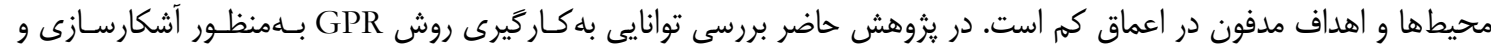

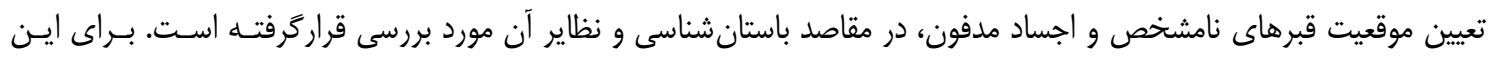

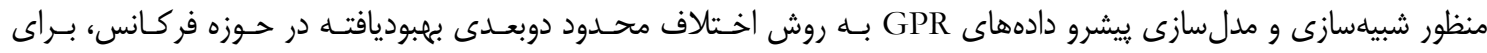

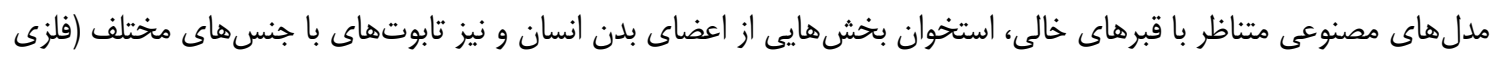

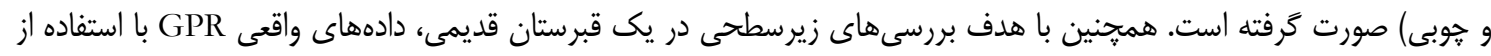

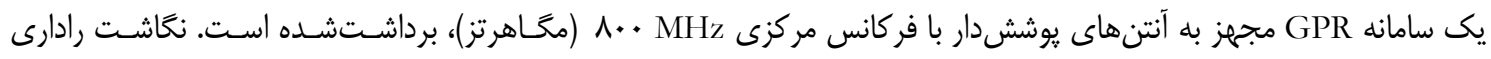
نهايى منطبق بر يكى از يروفيلهاى برداشتشده در اين منطقه، با اعمال توالى يردازشى مختلف شامل تصحيح استاتيك (سـاكن)،

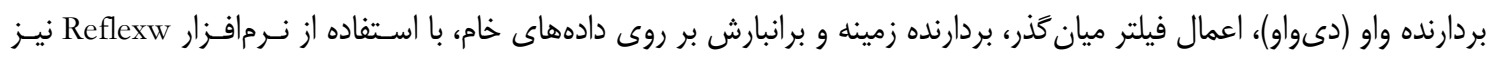

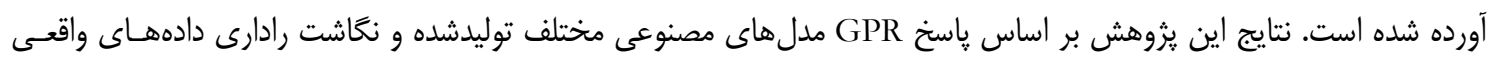

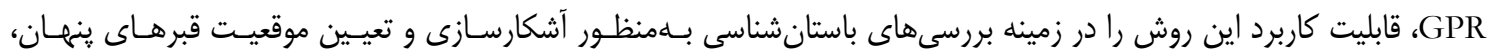

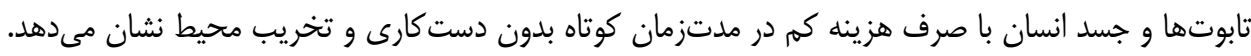

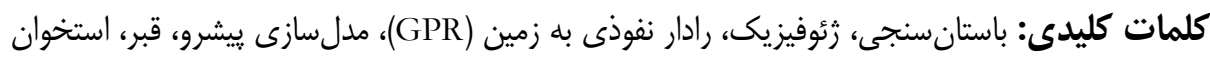

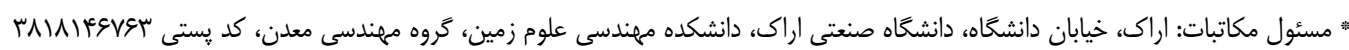
Rezahmadi@gmail.com : بست الكترونيكى C) حق نشر متعلق به نويسنده(كان) است و نويسنده تحت مجوز Creative Commons Attribution License به مجله اجازه مىدهد مقاله خاب شده را با ديخران به اشتراك بكذارد منوط بر اينكه حقوق مؤلف اثر حفظ و به انتشار اوليه مقاله در اين مجله اشاره شود. 
هدف از مطالعه حاضر كه يـك يـرَوهش كـاربردى

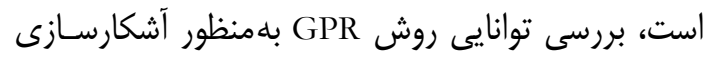

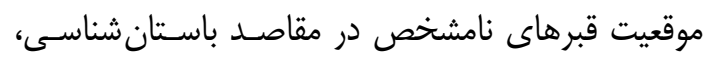

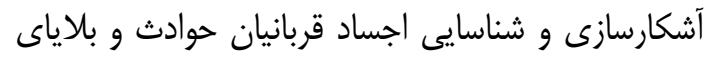

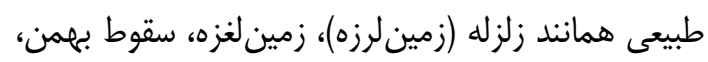

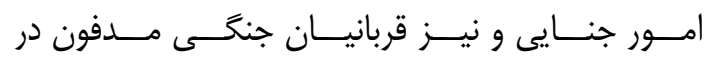

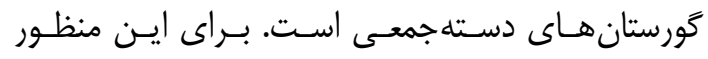

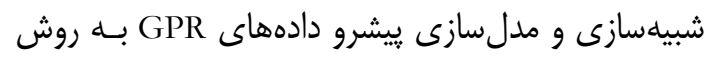
اختلاف محدود (Finite difference) دوبعدى بهبوديافتـه

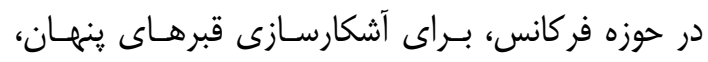

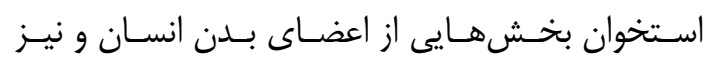
تابوتهاى با جنس هاى مختلف (فلزى و جوبى) صـورت كرفته است.

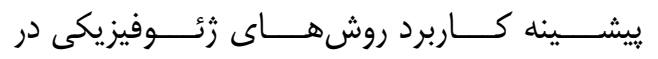
باستانشناسى به خند دهه قبل بازمى گردد. نخستين بـار

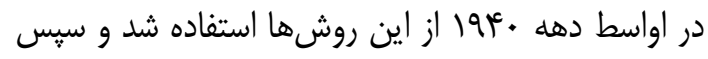

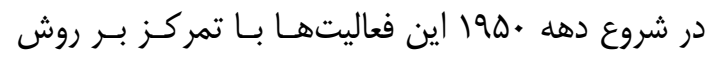
مغناطيسسنجى به انجام رسيد. از دهه •ـ191 استفاده از

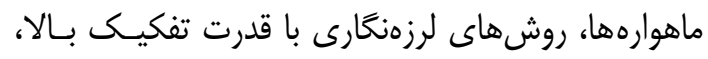

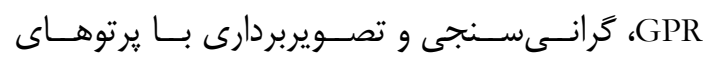
مادونقرمز، در دسترس باستانشناسان قرارگرفته اسـت.

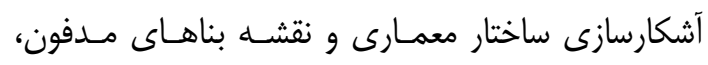

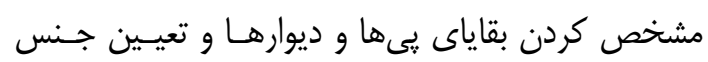

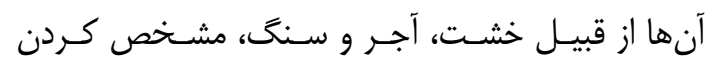

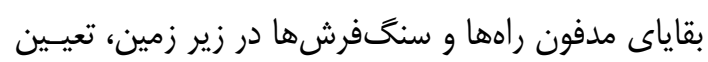

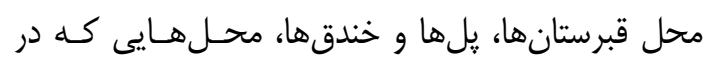

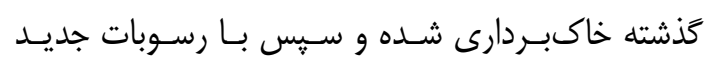

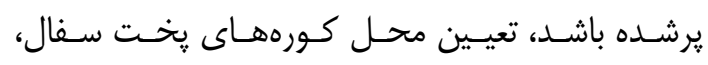
كورههاى ذوب فلز، محل خاكهاى سوخته و خاكستر و

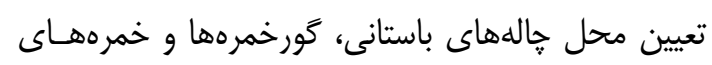

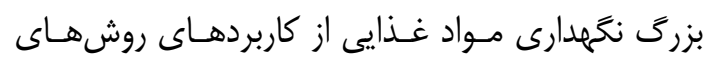
زئوفيزيك در باستانشناسى است [3].

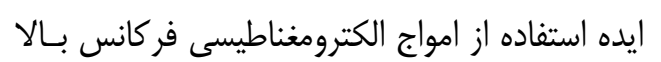

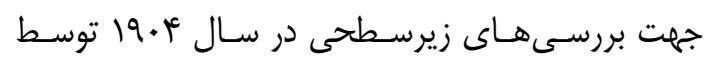

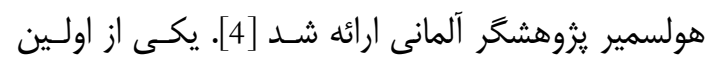

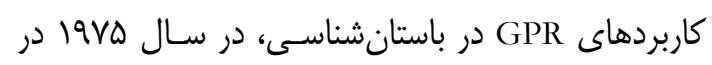

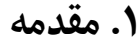

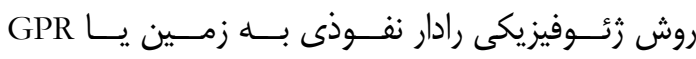

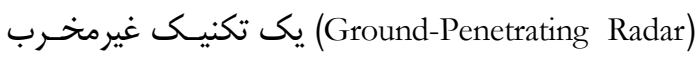
مؤثر و كارآمد است كه براى تصوير كردن اهداف و ويثزى ئى هاى اشياى مدفون در زير زمين (يا ساختارهاى دستسـاز

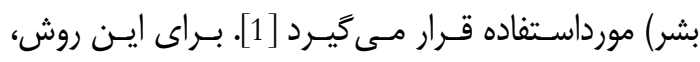

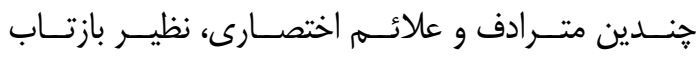

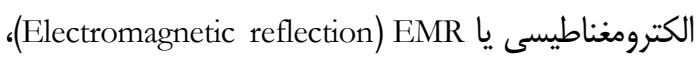
رادار مـرز زيرســـحى يــا Subsurface Interface SIR

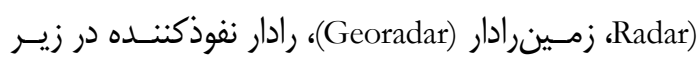
سـطح يـا Subsurface Penetrating Radar) SPR) و رادار خاى (Soilradar) وجود دارد [2].

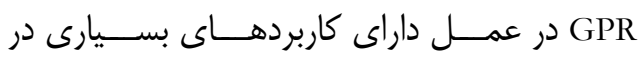
زمينههاى مختلف مهندسى و علـوم اسـت. مهـمتـرين

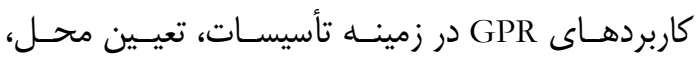

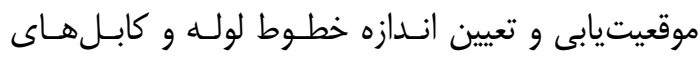

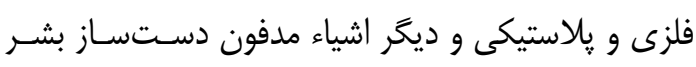

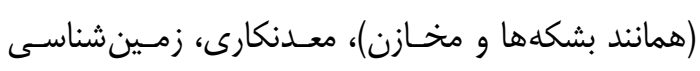

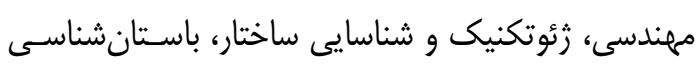

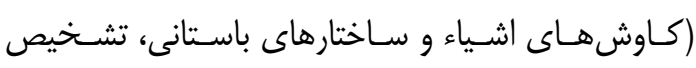

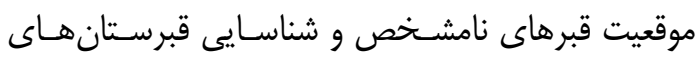
قديمى و تعيين محل جادههاى قديمى مدفون)، آزمودن بتن و كنترل محل ميلههاى مقاومسازى (ميلحرد) درون

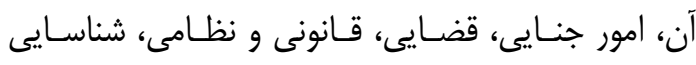

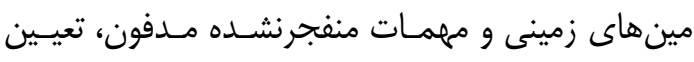

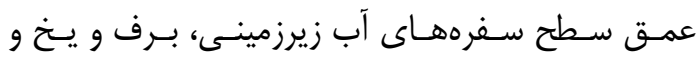
يخبندانشناسى و غيره است (وير ايش شده از [1]).

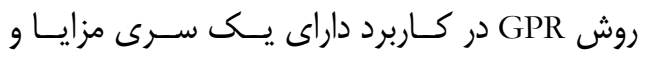

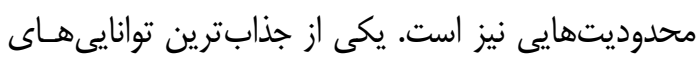

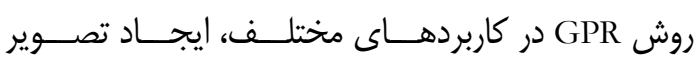

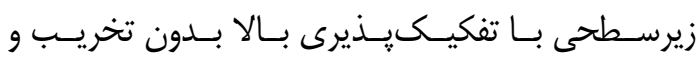

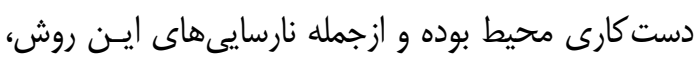

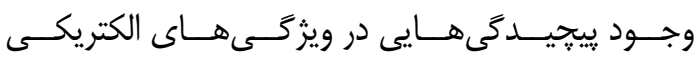
محيطهاست. اخر لايههاى رويى شامل مواد داراى هدايت الكتريكى خوب همانند رسهاى بسيار مرطوب و تركيبات

آهندار باشند، روش GPR ناموفق خواهد بود [1]. 
منجر به ميرايى سريع امواج و كاهش عمق نفـوذ امـواج

مىشود.

موفقيت كاوش و شناسـايى اسـتخوان بــنـ انسـان

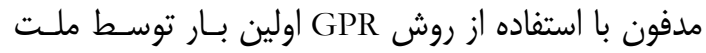

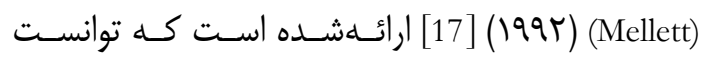

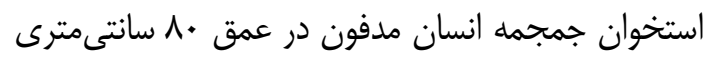

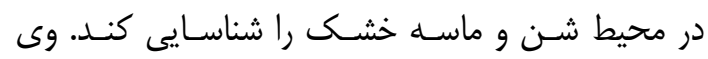

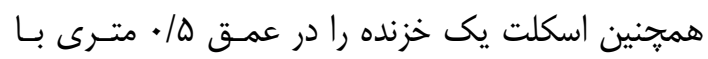

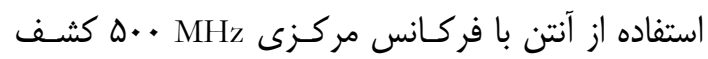

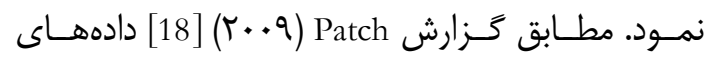

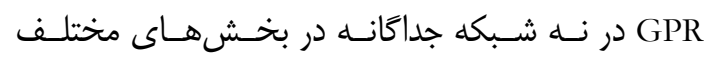

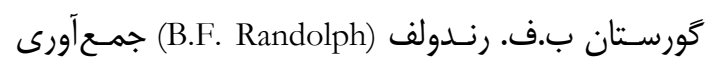

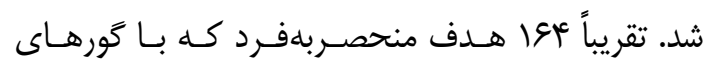

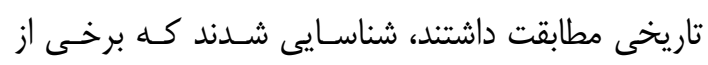

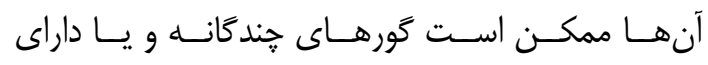

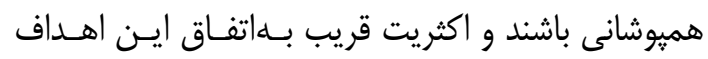

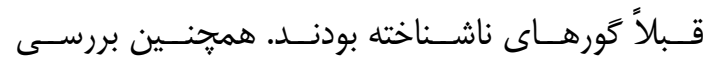

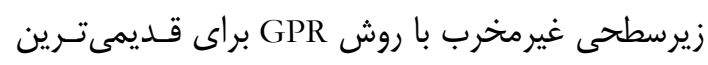

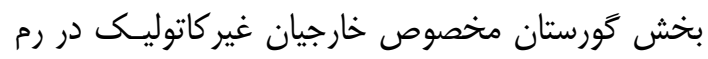

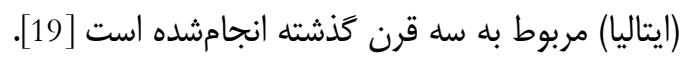

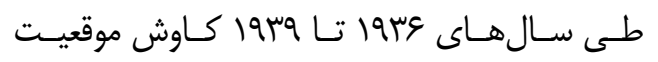

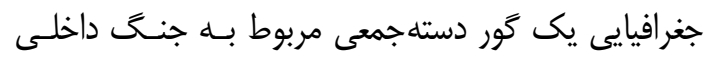

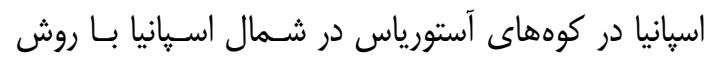

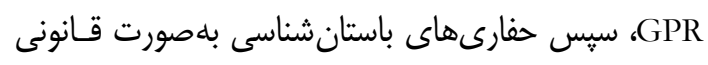

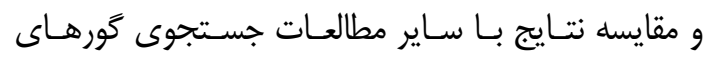
دستهمعى در محيطهاى مشابه كزارش شده اسـت [20].

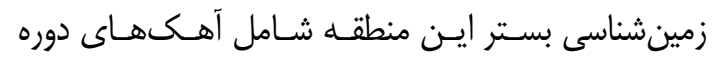

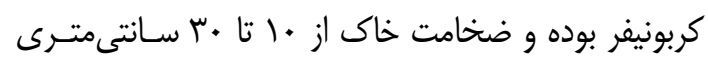

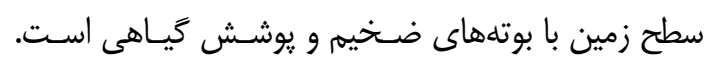

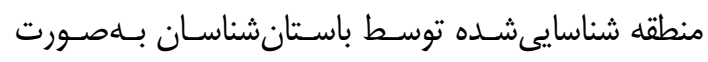

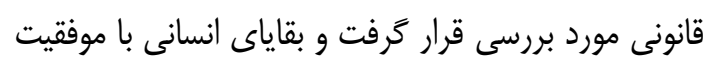

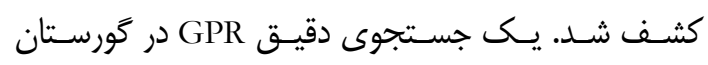

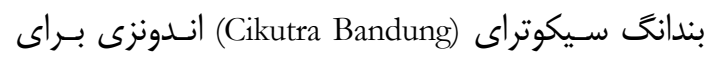

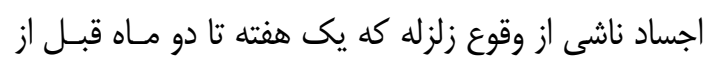

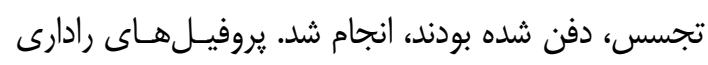
اين بررسى نشان از بىهنجارى دهـايى مبنـى بـــر احتمـال

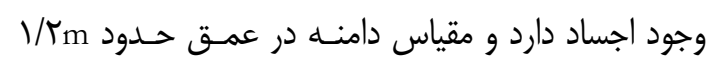

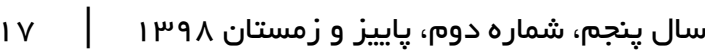

محوطه קكو كنيـون (Chaco Canyon) در نيومكزيكـوى (ئس

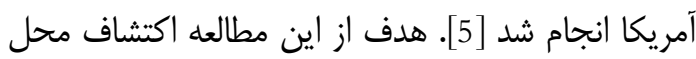

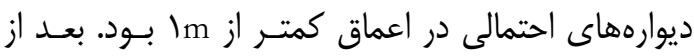

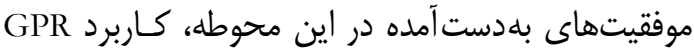
در سال 19V9 در هالاسلطان تكه (Hala Sultan Tekke)

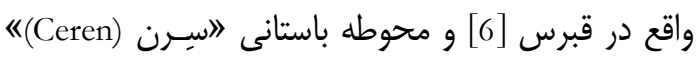

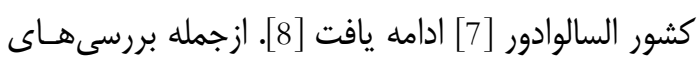

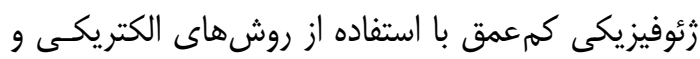

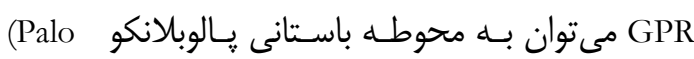
Blanko)

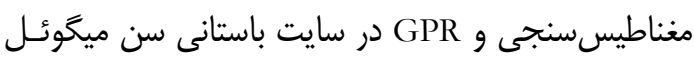

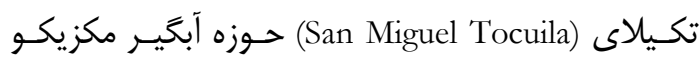

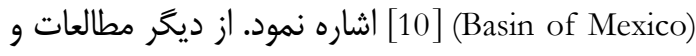

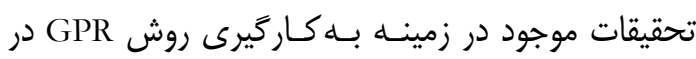

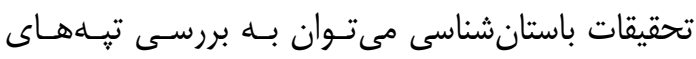

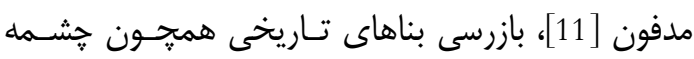

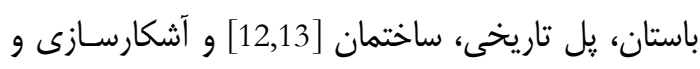

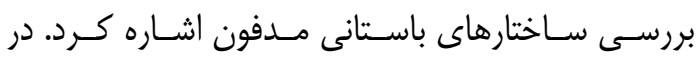

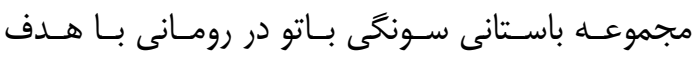
تشخيص و انتقال شواهد باستانشناسى موجـود، سـايت دواني

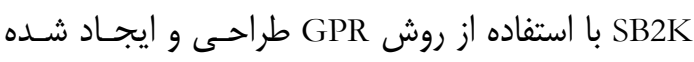

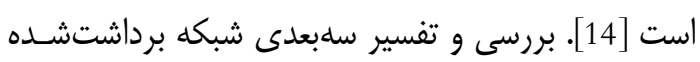
نشان مى دهد كه روش GPR در شناسايى اين ساختارها

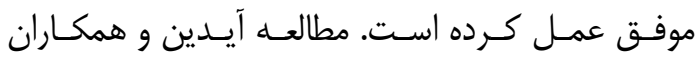

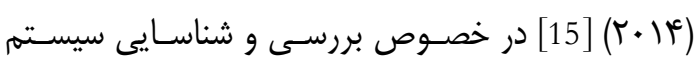

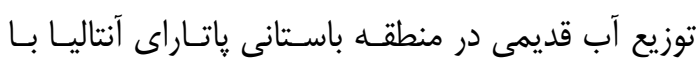

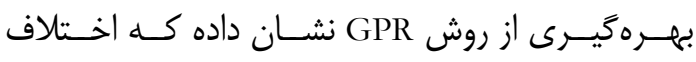

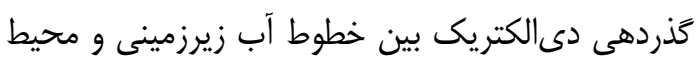

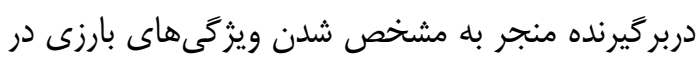

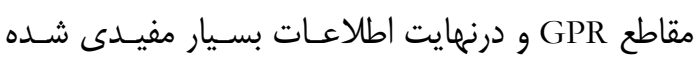

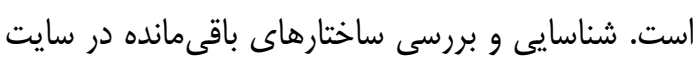

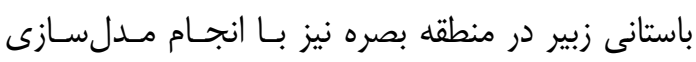

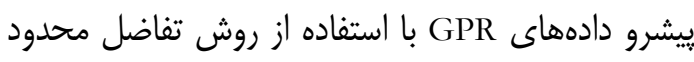

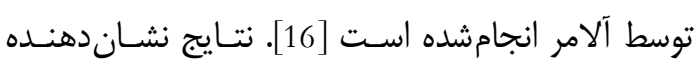
متفاوت بودن مــل ســازى از بازتـاب امـواج بـا سـاختار

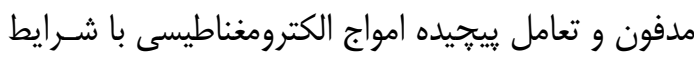
زيرسطحى است. همرجنين وجـود بنـايى بـا تـراكم بـالا 
مقاومت ويزه الكتريكى (ERT) در كاوشهـاى باسـتانى

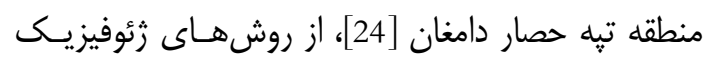

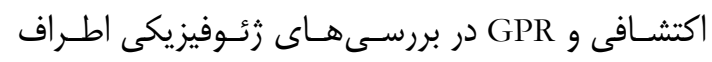

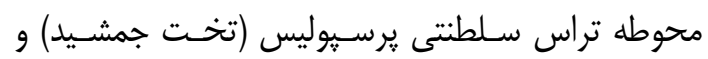
קغازنبيل [25] استفاده شده است.

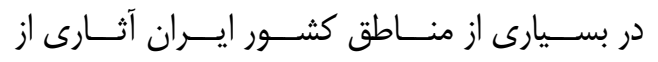

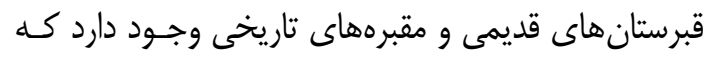

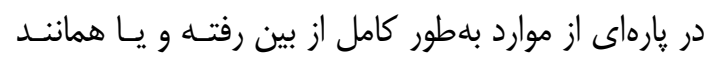

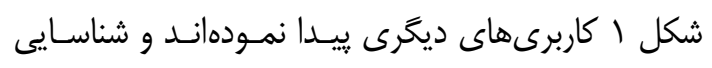

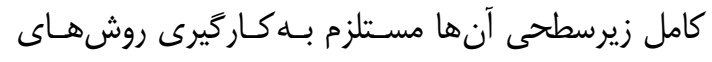

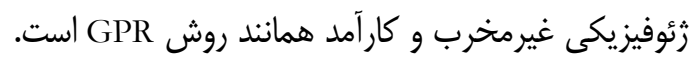

\section{r. تاريخجه تدفين و نحوه تجزيه جسد انسان}

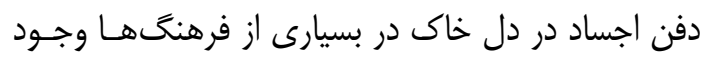

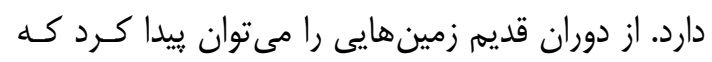

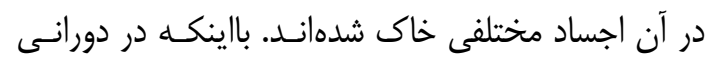

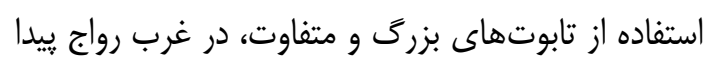

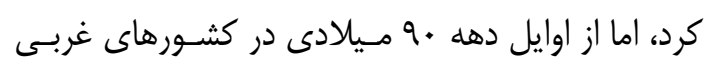

است كه با عمق اجسـاد دفن شــه سـازكار اسـت [21].

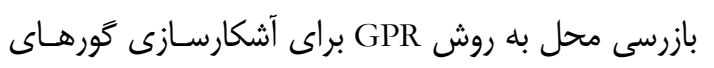

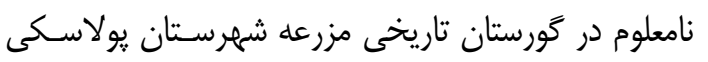

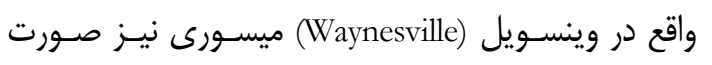

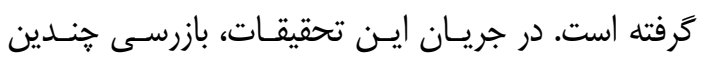

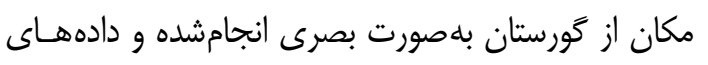

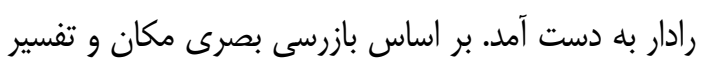

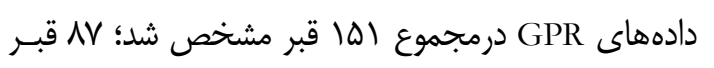

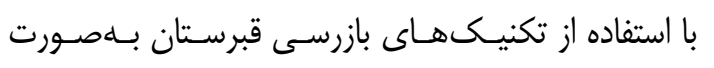

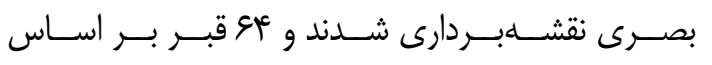
تجزيهوتحليل دادههاى GPR شناسايى شد [22]. در كشور ايران روش GPR در زمينه باستانشناسى دادمان

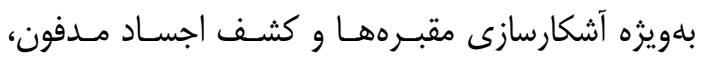

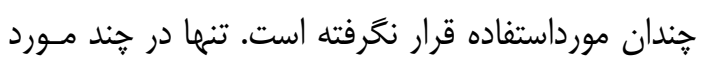

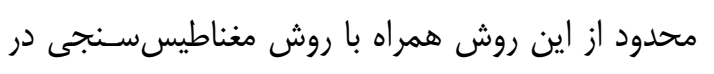

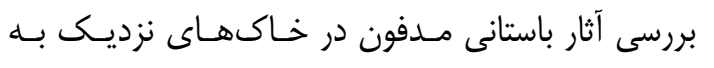

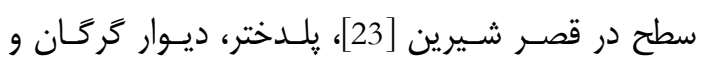

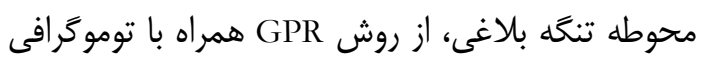
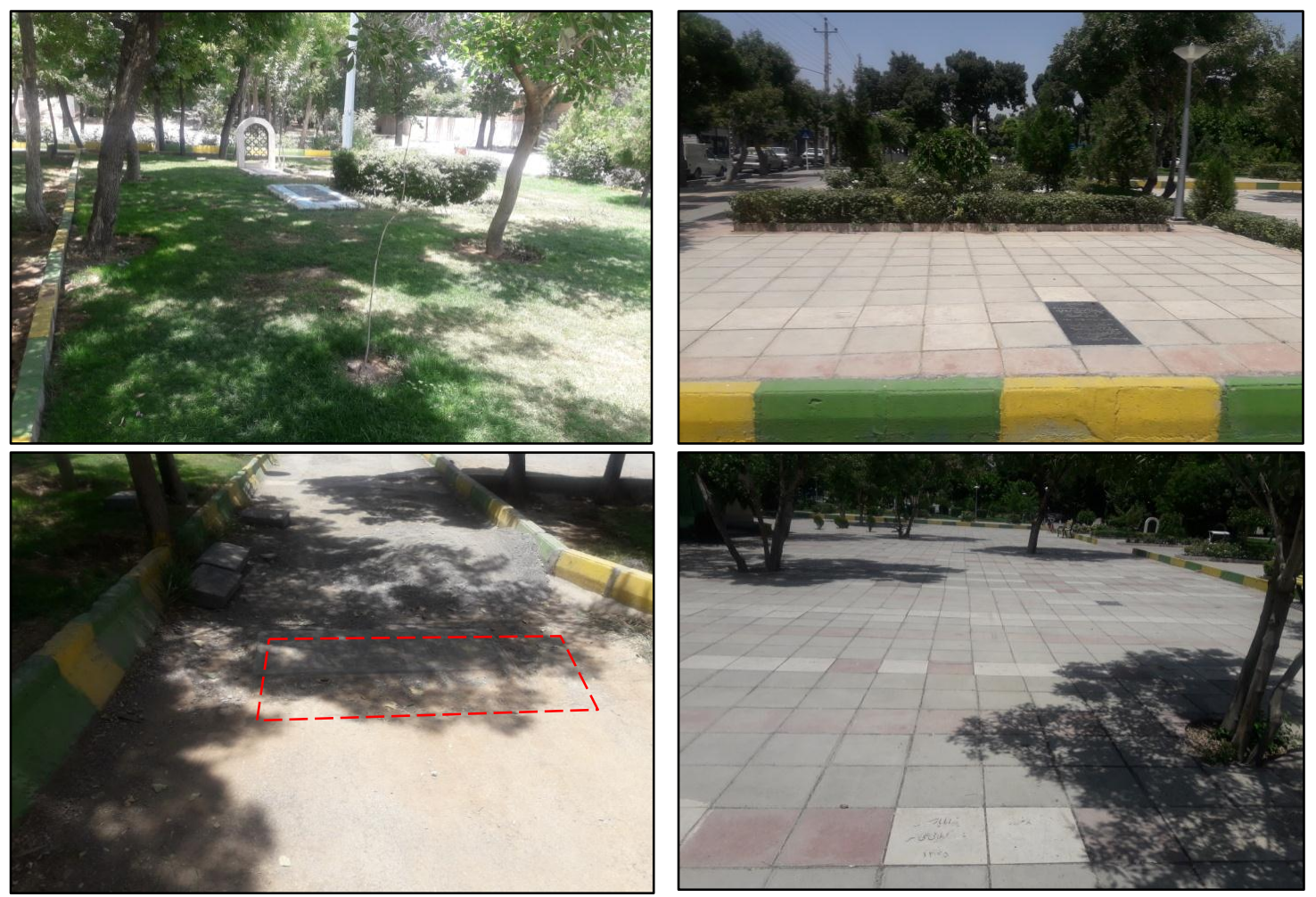

شكل ا: تصاوير مربوط به يكى از ياركهاى كلانشهر اراك. در تمام تصاوير آثار برخى از قبرهاى قديمى ديده مى إود.

Fig. 1: Images of one of the parks in Arak metropolis. In all images remains of some ancient graves can be seen. 


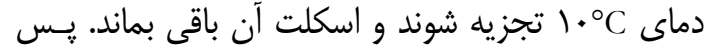

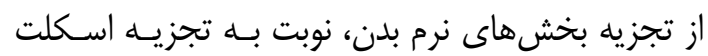

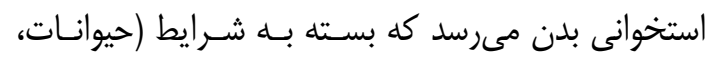

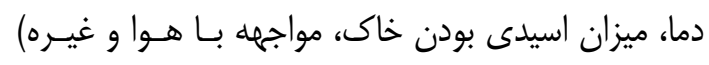

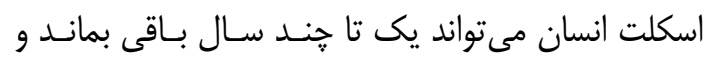

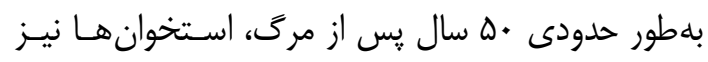

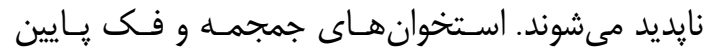

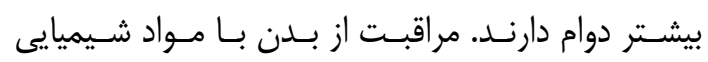

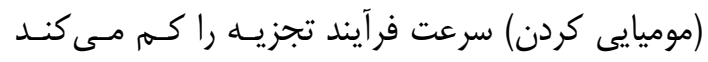

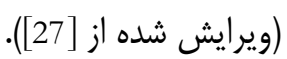

\section{س. اندازه و ابعاد تابوت و استخوان بدن انسان}

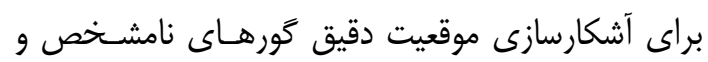

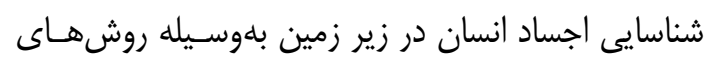
باستان زئوفيزيك، داشتن اطلاعات كامل از اندازه و ابعاد

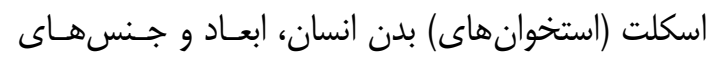

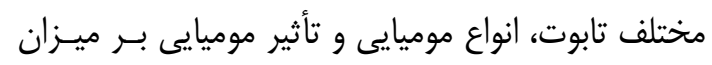

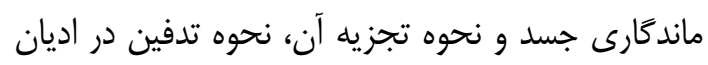
مختلف و عمق قراركيرى جسد در زيـــر زمــين موردنيـاز

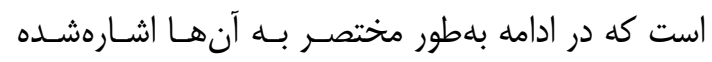

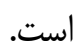

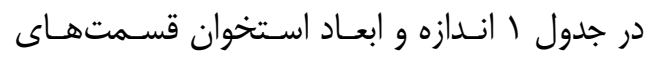
مختلف بلن انسان به تفكيك جنسيت آورده شده اسـت. مطابق دادههاى اين جدول بلهور كلى انـدازه استـتخوان

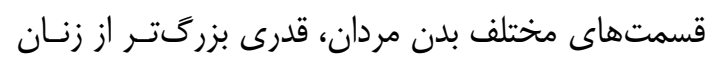

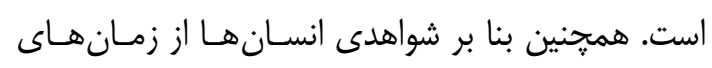

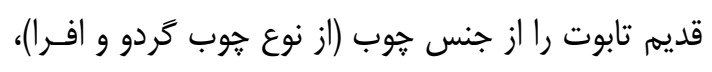

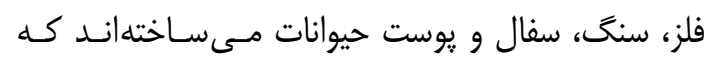

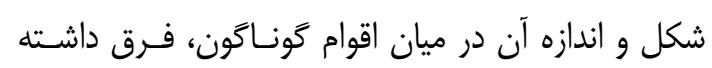

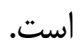

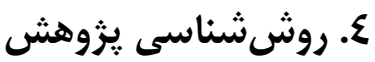

\section{ع-1 أ. مبانى نظرى و فيزيكى روش}

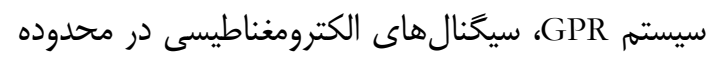

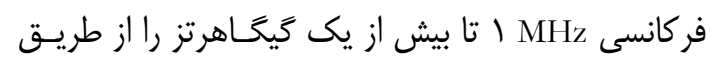

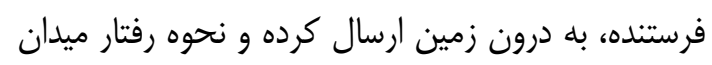

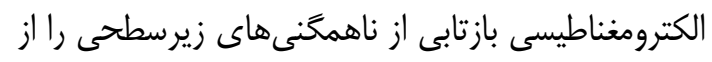

نيز كمتر از تابوت استفاده مىشود؛ يا تابوتها از مـوادى

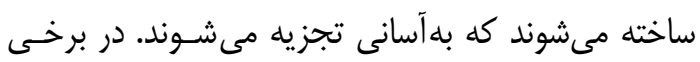

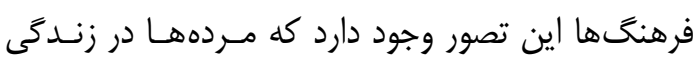

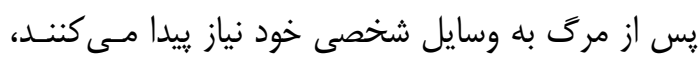

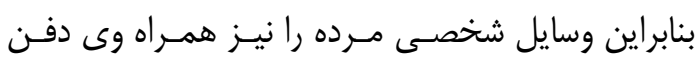
مى كنند (ويرايش شده از [26]).

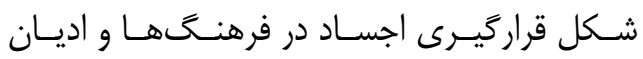

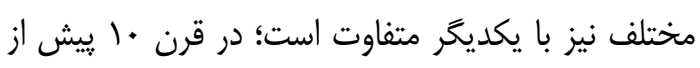

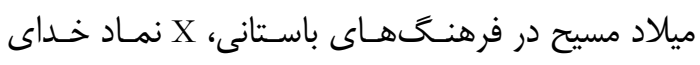

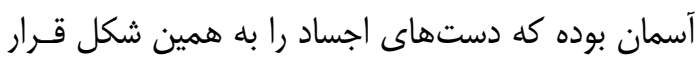

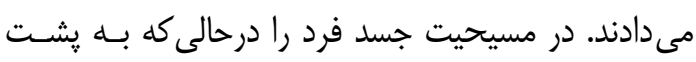

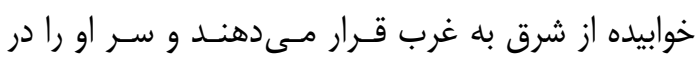

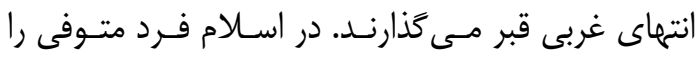

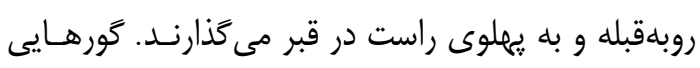

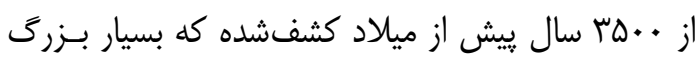

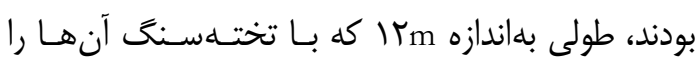
مشخص مى كردند، در اين كورها صد جنازه جا مى كَرفت

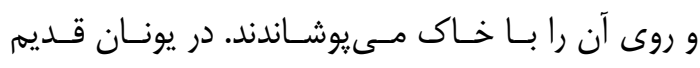

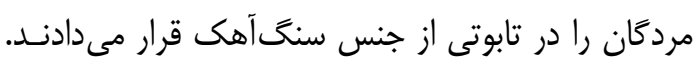

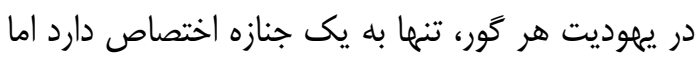
در ايران با افزايش جمعيت، بلهتدريج از اوايل دهه ينجـاه

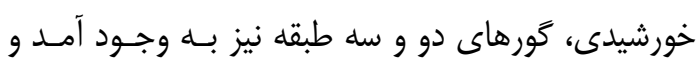

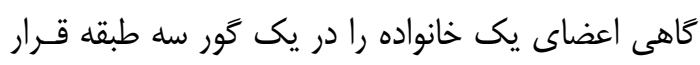

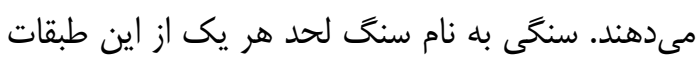

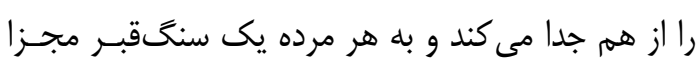

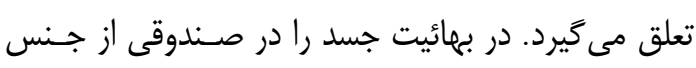

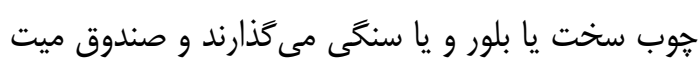

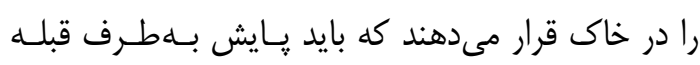

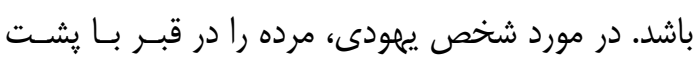
بلهسوى بيتالمقدس مىخوابانند (ويرايش شده از [26]).

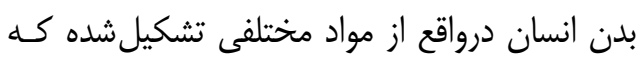
جنس، مقاومت و تركيب هر كـدام از آنهـا بــا يكـديخر

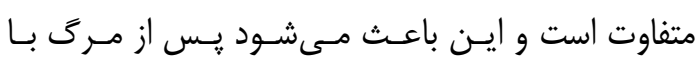

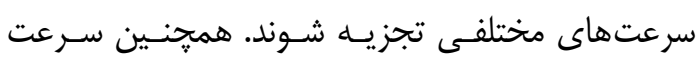

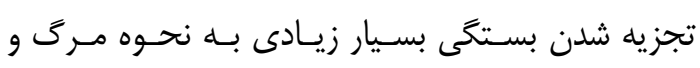

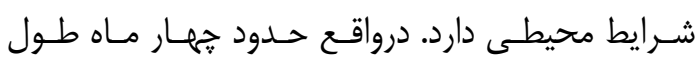

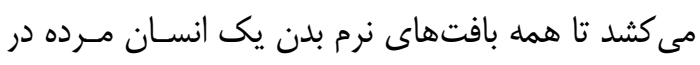

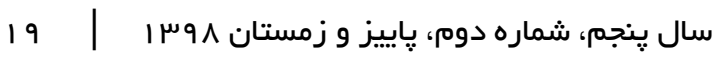


جدول ا: اندازه و ابعاد استخوان قسمتهاى مختلف بدن مردان و زنان [28,29]

Table 1: Bone size of various parts of men's and women's body [28,29]

\begin{tabular}{|c|c|c|c|c|c|}
\hline $\begin{array}{c}\text { حجم (ml) } \\
\text { Volume (ml) }\end{array}$ & $\begin{array}{c}\text { قطر } 1 \mathrm{~cm} \\
\text { Diameter }(\mathrm{cm})\end{array}$ & $\begin{array}{c}\text { (cm) عرض } \\
\text { Width (cm) }\end{array}$ & $\begin{array}{c}(\mathrm{cm}) \text { طول } \\
\text { Length }(\mathrm{cm})\end{array}$ & $\begin{array}{c}\text { نام استخوان } \\
\text { Name of bone }\end{array}$ & جنسيت \\
\hline & 5 & 6.6 & 33.5 & $\begin{array}{c}\text { بrm } \\
\text { Arm }\end{array}$ & \multirow{6}{*}{$\begin{array}{l}\text { Male } \\
\text { Male }\end{array}$} \\
\hline & 2.6 & 3.4 & 26.5 & $\begin{array}{c}\text { ساعد } \\
\text { Forearm }\end{array}$ & \\
\hline & 2.3 & & 48 & $\begin{array}{c}\text { ران } \\
\text { Thigh }\end{array}$ & \\
\hline \multirow[t]{4}{*}{1548} & & 15 & 18.6 & جمجمه & \\
\hline & \multirow[t]{2}{*}{3.4} & 7.41 & 36.5 & ساق گ & \\
\hline & & 1.3 & 45 & $\begin{array}{l}\text { ستون فقرات } \\
\text { Spinal cord }\end{array}$ & \\
\hline & 4.4 & 5.8 & 30.5 & $\begin{array}{c}\text { بازو } \\
\text { Arm }\end{array}$ & \multirow{4}{*}{$\begin{array}{c}\dot{j} \\
\text { Female }\end{array}$} \\
\hline \multirow[t]{3}{*}{1425} & 2.2 & 2.9 & 23.8 & $\begin{array}{c}\text { ساعد } \\
\text { Forearm }\end{array}$ & \\
\hline & & 14.8 & 17.9 & جمجمه & \\
\hline & & 13 & 43 & $\begin{array}{l}\text { ستون فقرات } \\
\text { Spinal cord }\end{array}$ & \\
\hline
\end{tabular}

انرزى موج راديويى كه به سطح شىء برخورد مسى كنـد، إنسا.

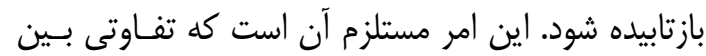

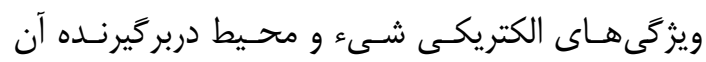

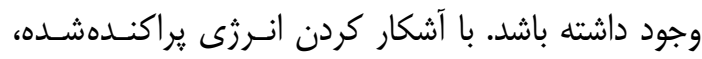
تعيين محل و موقعيت جشمههاى يراكنده كننده انـرزى،

|مكانيذير مىشود [1]. متداولترين شيوه نمايش دادههـاى GPR، نمـايش دامنه سيخنال امواج EM باز تابى، در مقابل زمـان تـأخير

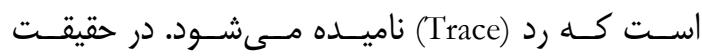
رخدادهاى فضـاى سـهبعــى درون يـك ركـورد زمـان يكبعدى ترسيم مىشوند (شـكل r). يلاريتـه سـيخنال

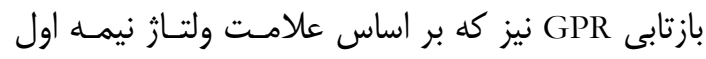

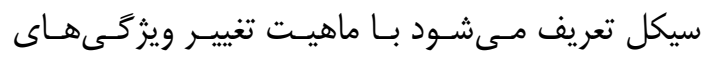
الكتريكى (بهويزه ع) كنترلشده و در تفسير دادهها بسيار

$$
\text { مفيد است [1]. }
$$

در حالت كلى، نكاشـت رادارى (Radargram) يـــ

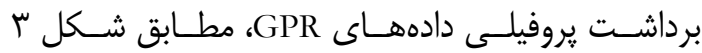

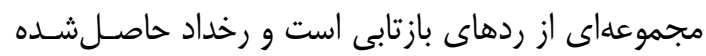

طريق گيرنده، آشكار مى كند. سيكنال منتشرشده كـه در

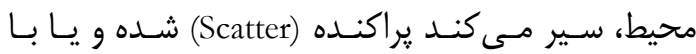
تغييراتى در مقاومت الكترومغناطيسى (Impedance)، بـا

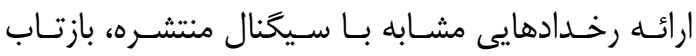

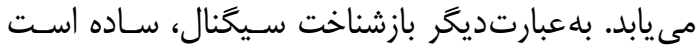

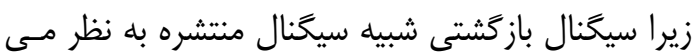

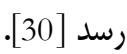

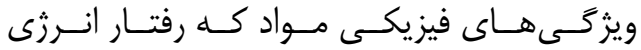
الكترومغناطيسـ را در يـك محسيط كنتـرل مسى كنتـد،

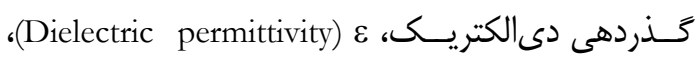
نفوذيـذيرى مغناطيسى، $\mu$ (Magnetic permeability) و هدايت الكتريكى، $\sigma$ (Conductivity) هسـتند. تغييـرات

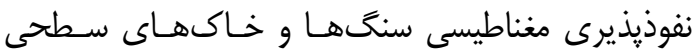

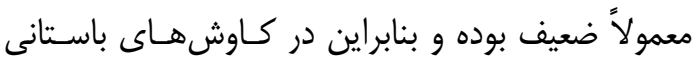

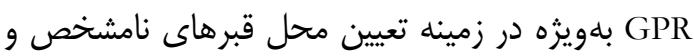

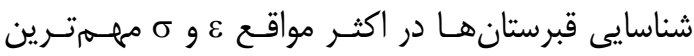
يار امترها هستند.

بلممنظور آشكارسازى يك شىء بايستى بخشـى از

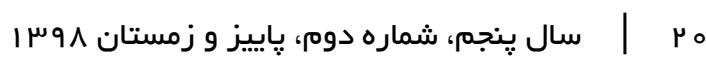




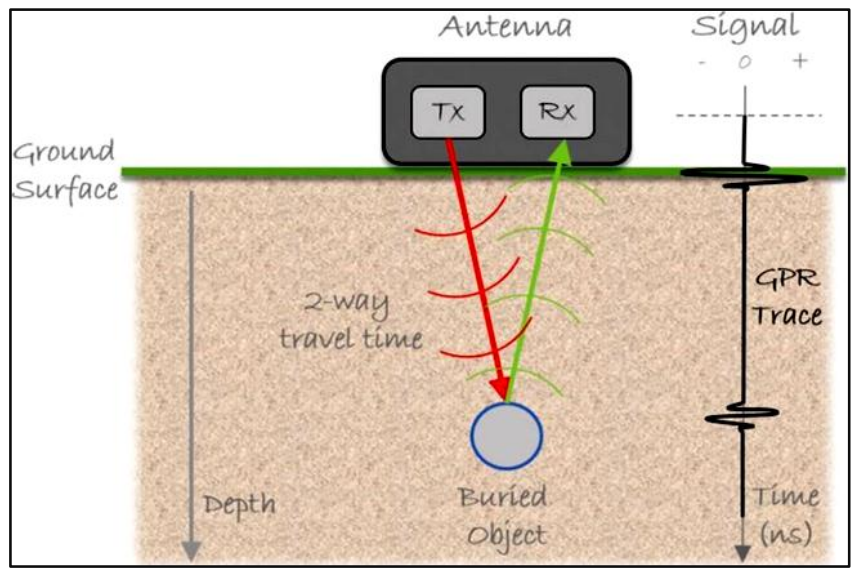

شكل ז: دادههاى نوعى ثبتشده توسط سيستم GPR. براى تحليل، دامنه در مقابل زمان تأخير ترسيه مىشود [31].

Fig. 2: Typical data recorded by a GPR system. For analysis amplitude is plotted against the delay time [31].

برداشت در راستاى يك يروفيل و معمولاً با يك فاصـله

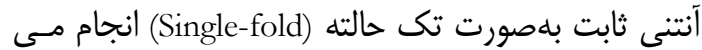
كيرد. بيشتر سيستههاى GPR از آنتنهاى جداكانه براى تابت

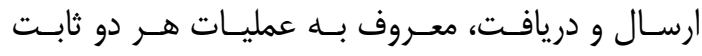
استفاده مى كنند؛ اكرجه ممكن است آنـتنهـا

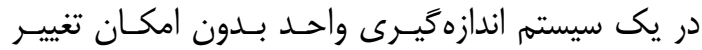
جدايش آنتسى جـاى گيرنـــ (تـى ثابـت: Monostatic). متداولترين شيوه برداشت، يروفيلزنى بازتابى تك حالته با فاصله ثابت (Common distance) است.

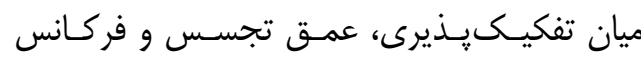

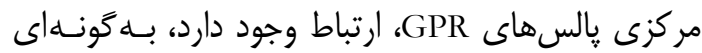
كه با افزايش فر كانس مركزى، تفكيكيـــيرى افـزايش

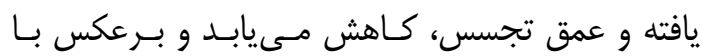

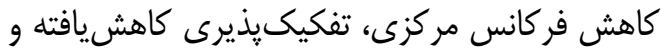

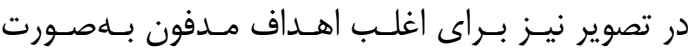
هذلولى است. براى آشكارسازى فرض مىشود كه دامنه

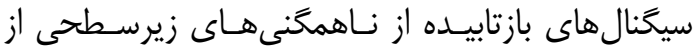

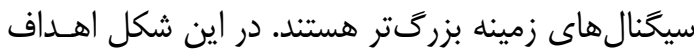

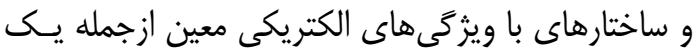

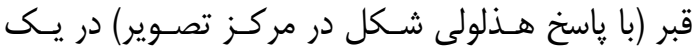
محيط با ويزگى الكتريكى متفاوت مشخص فشدهاند. برداشتهاى GPR بـهـصـورت سـه شـيوه (Mode)

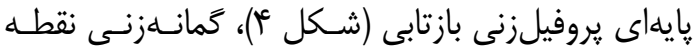
ميانى مشترى (Common Mid-Point (CMP) و عبدور از ميـان يـك محسيط و دريافت (Transillumination)

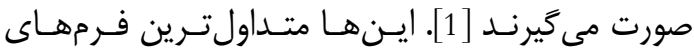

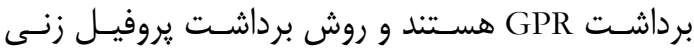

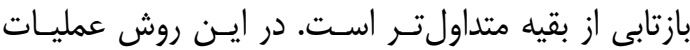

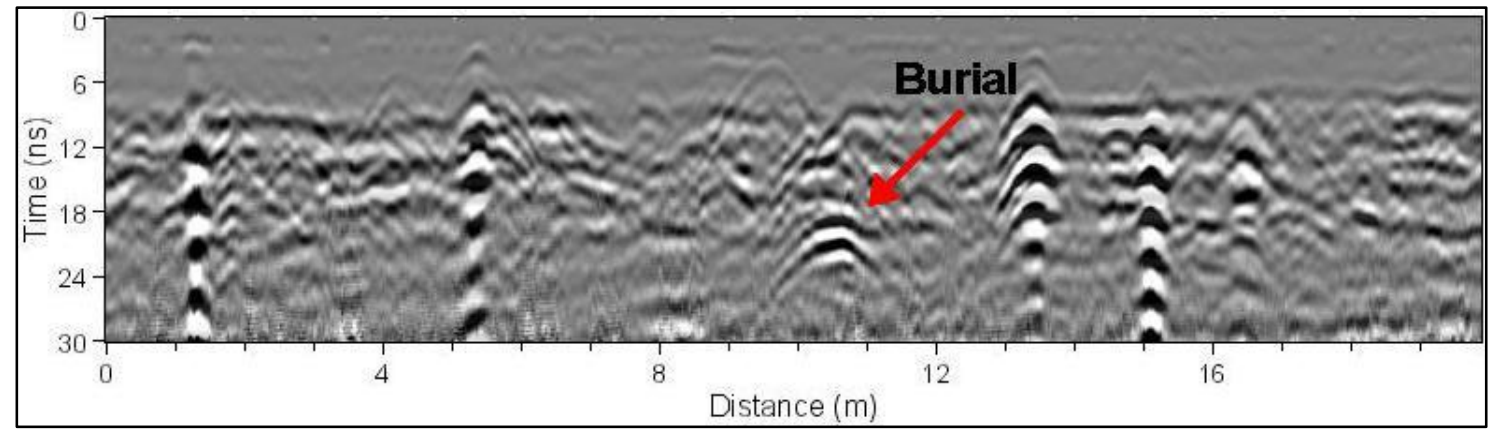

شكل سّ: نكاشت رادارى دادهاى واقعى GPR بر روى اهداف مدفون و رخدادهاى مربوطه در تصوير بلصورت هذلولى. ياسخ هذلولى شكل در

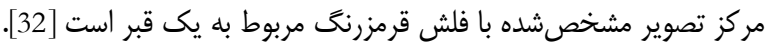

Fig. 3: Radargram of real GPR data on buried targets and related events as hyperbolic in the image. Hyperbolic response at the center of the image shown by red arrow corresponds to a grave [32].

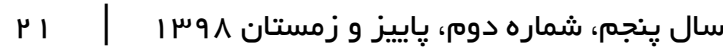



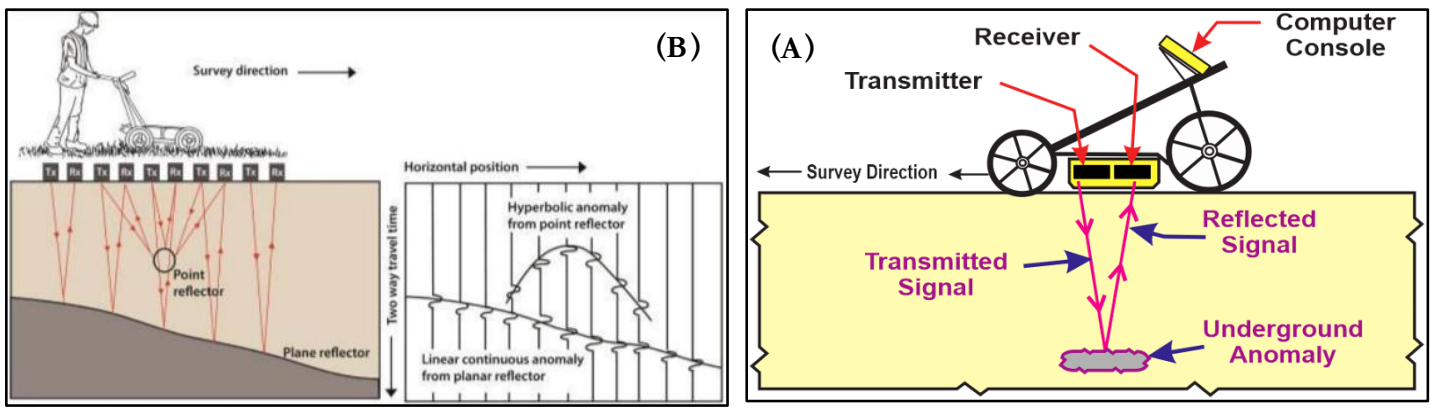

شكل ع: نمايش سيسته GPR، نحوه برداشت دادهاى GPR به روش يروفيلزنى باز تابى با فاصله آنتى ثابت و رخدادهاى متداول در ياسخ

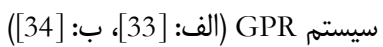

Fig. 4: Illustration of GPR system, the procedure of GPR data acquisition through reflection profiling with bistatic antennae and common events in the response of a GPR system (A: [33], B: [34]

جهتيافتكى ساختار دوبعدى معلـوم باشـــ، فاصـله بـين

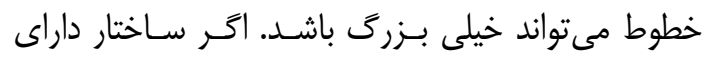

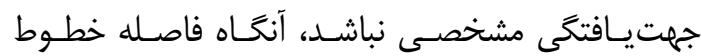
برداشت بايد به اندازه فاصله ايستخاهى باشد تا اطمينـان

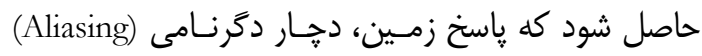

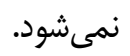

بلمطور كلى مطـابق شـكل ثَ(ب) رخــداد حاصـل در

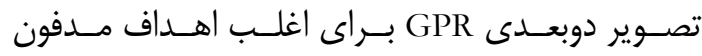
نقطهاى، كروى و استوانهاى، بلهصورت هـــلولى و بــراى ناهمخنىهاى صفحهاى افقى يا مايل همانند مرز لايهها، بلمورت يك خط راست است.

\section{ع-ז. بله كارَيرى روش GPR در زمينه آشكار سازى قبر هاى نامشخص}

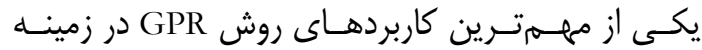

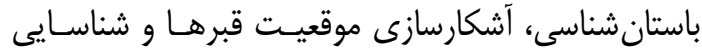

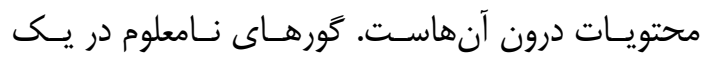

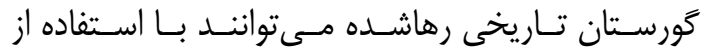

عمق تجسس، افزايش مىيابد. انتخاب فركانس عملكرد

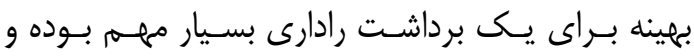

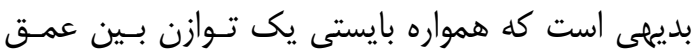

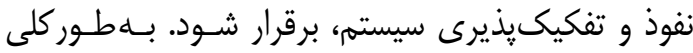

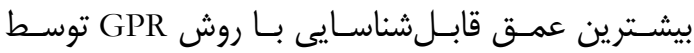

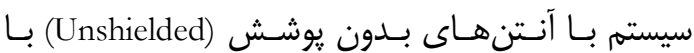

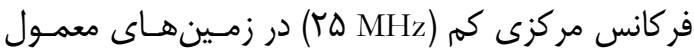
بدون حضور روبارههاى مرطوب و هادى و مـواد جـاذب مداذب امواج الكترومغناطيسى، حدود m D ه است.

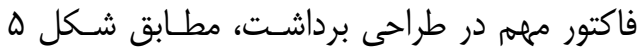
ايجاد يك شـبكه برداشـت و سيسـتم مختصـات اسـت.

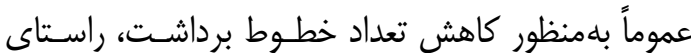

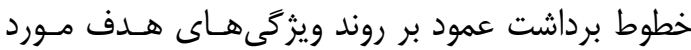

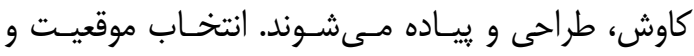

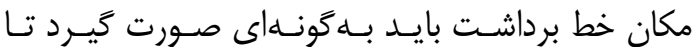
آشكارسازى هدف، بيشينه شود. اخر هـــف داراى امتـداد مشخصى باشد، تمام خطوط برداشت بايد عمود بر امتداد

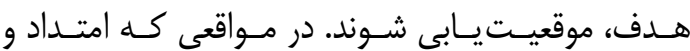

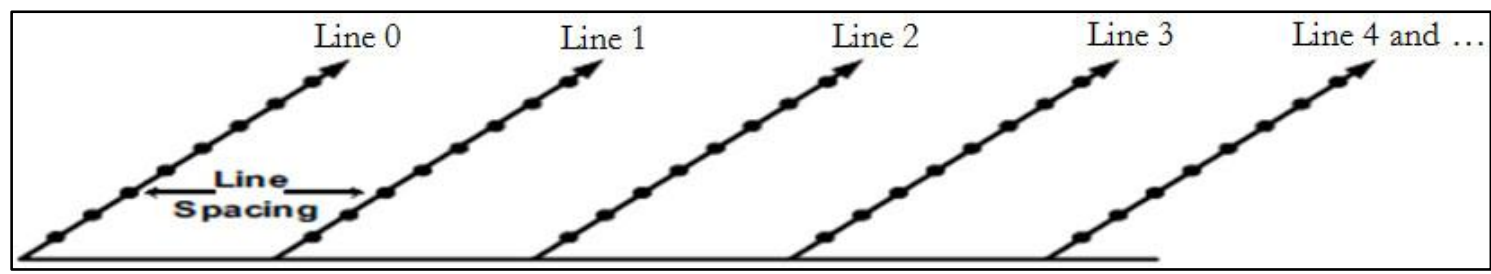

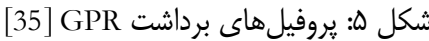

Fig. 5: GPR surveyed profiles [35] 


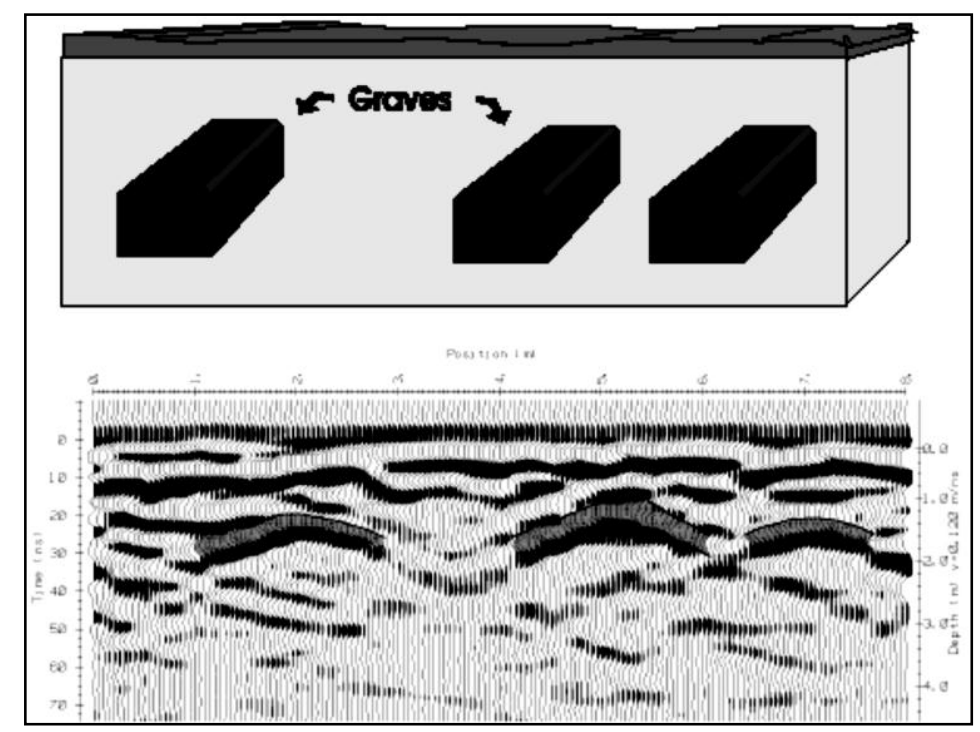

شكل ك: شكل طرح وار سه قبر همراه با پاسخ سيستم GPR مربوطه [1]

Fig. 6: Schematic picture of 3 graves with the related GPR system response [1]

شود تا اين هسته مدلسازى ييشرو منجر بــه شناسـايى رفتار مدلهاى مختلف در ياسخها شده و عمليات تفسير

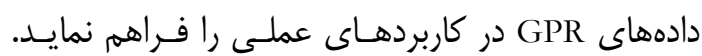

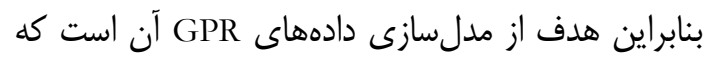

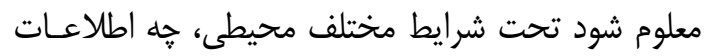

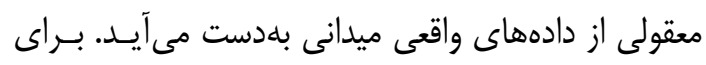

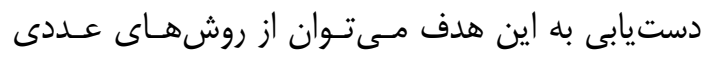

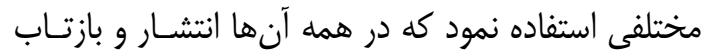
امواج GPR در درون زمين، بر اساس رفتار امـواج EM و

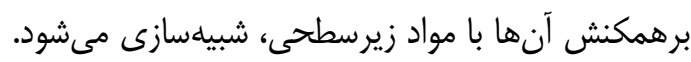
در ميان روشهاى عـددى مختلـف، روش تفاضـل

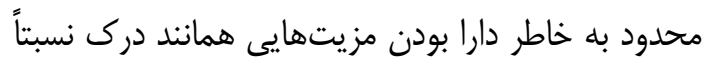

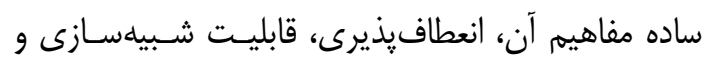

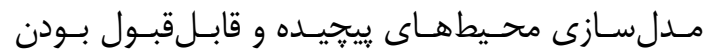

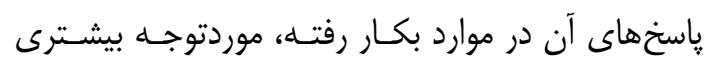

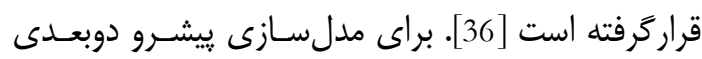

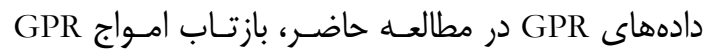

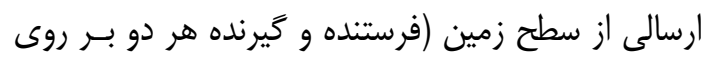

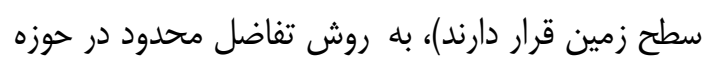

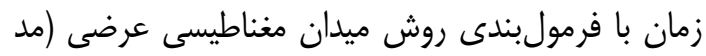

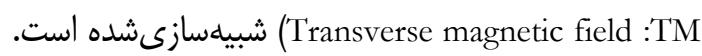

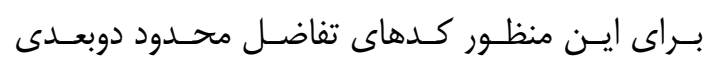

تكنيكهاى بازرسى محل بـه روش GPR آشكارسـازى

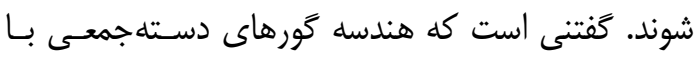
كورهاى منفرد، بسيار متفاوت است. سيستمهاى GPR بال كناس

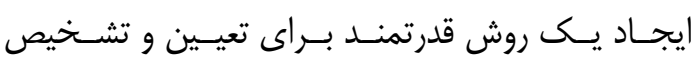

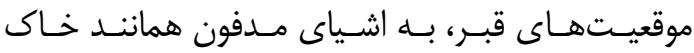

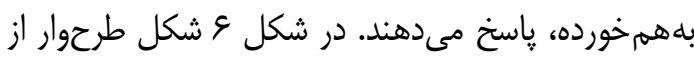

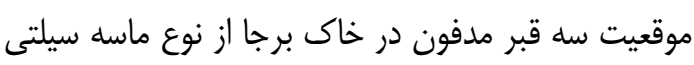

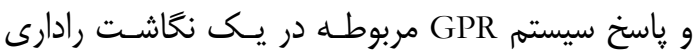
نشان دادهشده است.

\section{ع-"َ. فر آيند مدلسازى ييشرو دادههاى GPR}

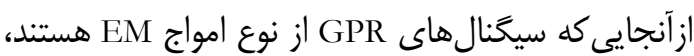

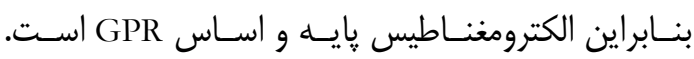

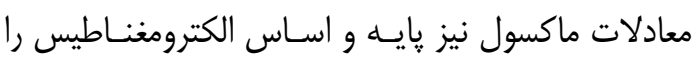

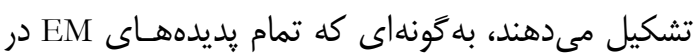
مقياس ماكروسكويى توسط اين معادلات قابل توصـيف

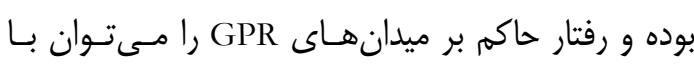
اعمال شر ايط اوليه و شرايط مرزى مناسب، شـبيهسـازى ميلى

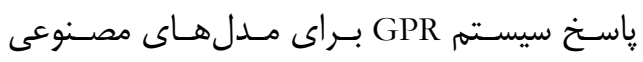

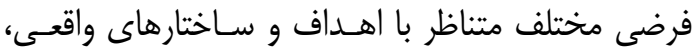

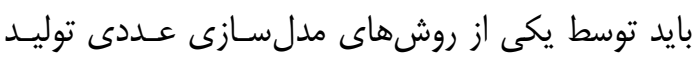


مستقيم (هوا و زمين) كه همواره بلهـورت يـك رخــاد خطى افقى است، از ياسخ حذف كَرديده است.

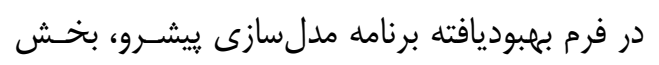

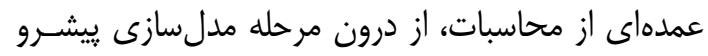

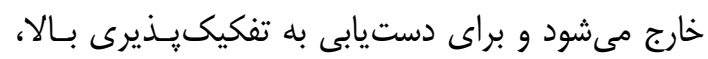

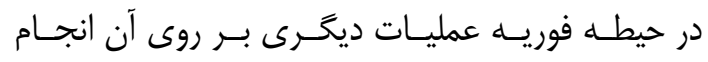

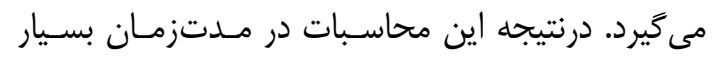

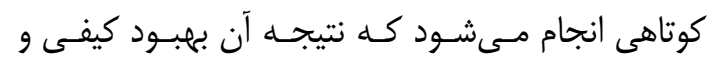

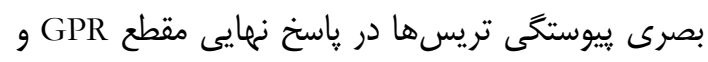
توليد ياسخ با تفكيكيذيرى زياد است.

\section{ع-ع. شبيهسازى پاسخ GPR مدلهاى}

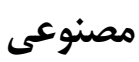

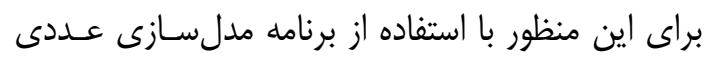

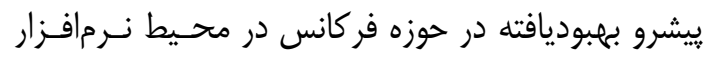

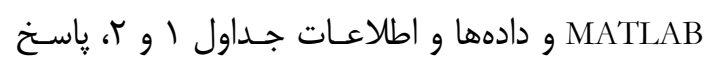
GPR با تفكيكيذيرى زياد براى مـدلهـاى مصـنوعى ادهات

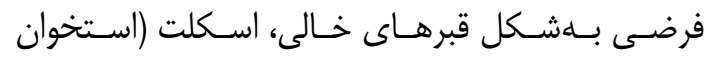

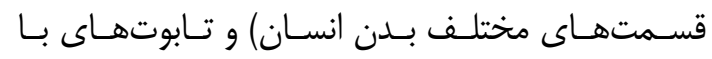
جنس هاى مختلف با هدف شناسـيى موقعيـت قبرهـا و و كاوش اجساد انسان مدفون در زير زمين، شبيهسازى شده

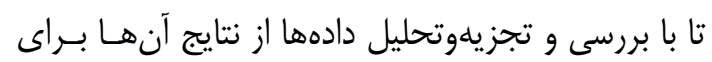
تفسير نغاشتهاى رادارى واقعى استفاده شود. در جدول

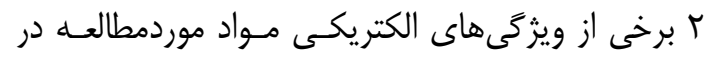

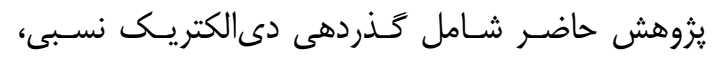
هدايت الكتريكسى و سـرعت سـير امـواج EM (نوعـاً در

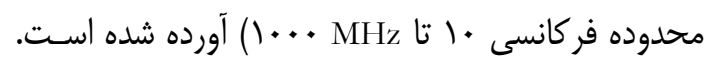
بلممنظور انطباق بيشتر نتايج شبيهسازى با عمل، مقـادير

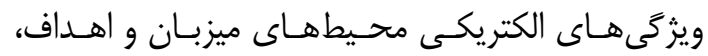
واقعبينانه انتخابشده است. در مدل سازى ييشروى مصنوعى دادهها، موارد زيـر

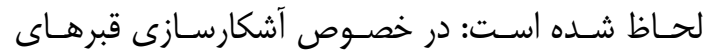

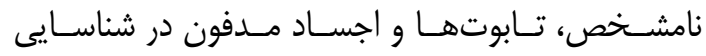

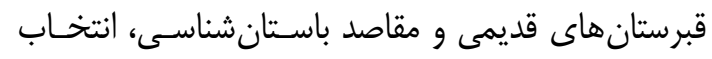

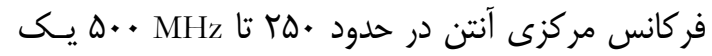

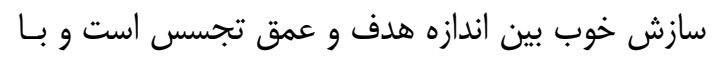

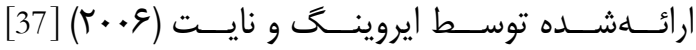

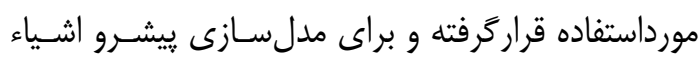
مصنوعى فرضى متناظر با اهداف متداول در كاربردهـاى مدرى

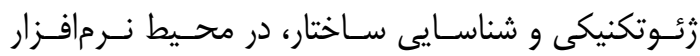

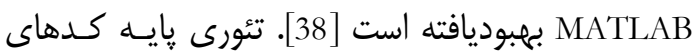
مدلسازى ييشرو GPR، معادلات كرل ماكسول (قانون

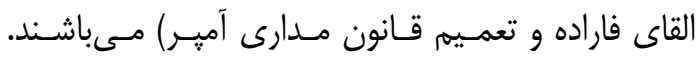

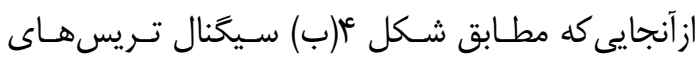

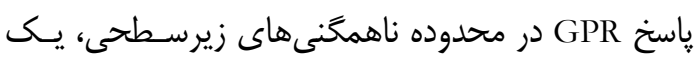

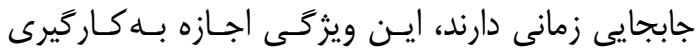

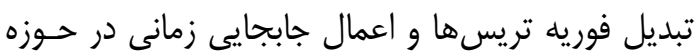

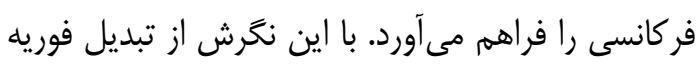

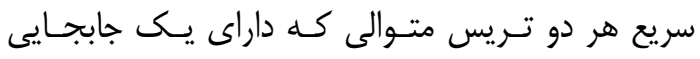

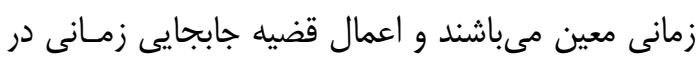

حيطه فوريه مطابق رابطه ( استفادهشه است [38].

$$
f\left(t-t_{0}\right) \stackrel{F}{\Leftrightarrow} \quad e^{-i \omega t_{0}} F(\omega)
$$

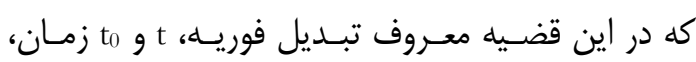
است

در اين روش ابتدا بيشترين مقدار دامنه هـر تـريس

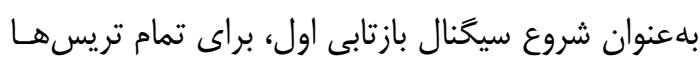

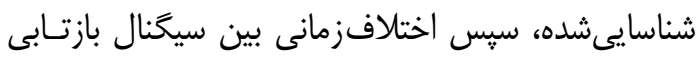

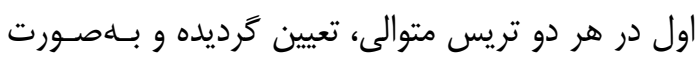

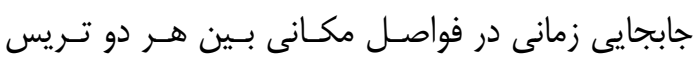

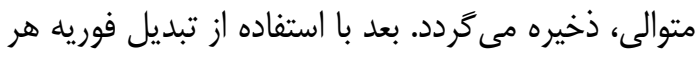

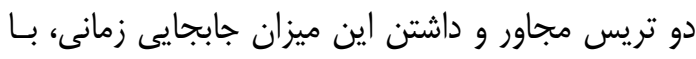

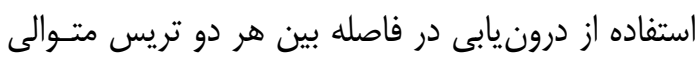

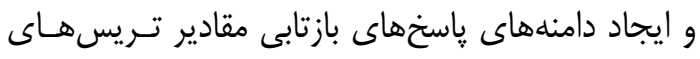

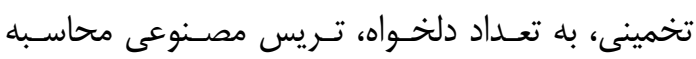

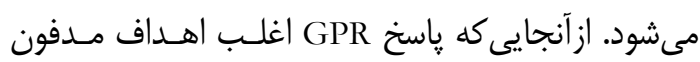

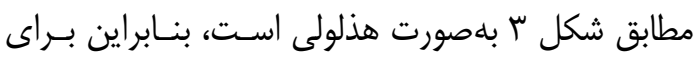

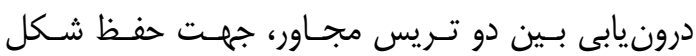

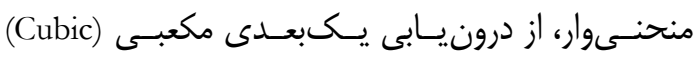

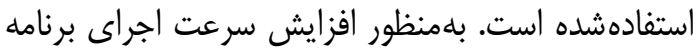

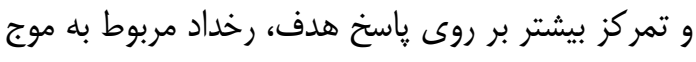


نشان دادهشده است. محيط ميزبان در اين حالـ خـاك

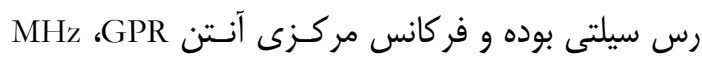

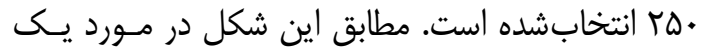
قبر خالى، קاسخ سقف مدل بهصورت يك شبه هذلولى با بالِ

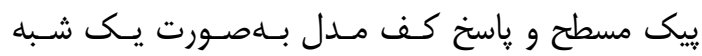

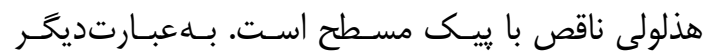
تصوير دو شكل هذلولى كه توسط خـط بازتابنـده افقى نـى جداشده است، قابـلمشــاهده اسـت. بنـابر اين در تفسـير

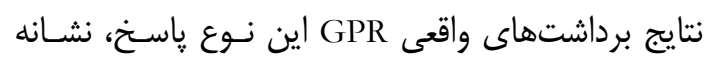
حضور يك ساختار مكعبى شكل همانند يك قبر مـدفون است. در ياسخ كف قبر، تا حدودى تضعيف سـيخنال در

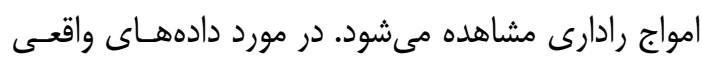
در اثر وجود نوفه (يارازيت)، اخـتافل بيشـترى در دامنـهـ بازتابهاى سقف و كف قبر ديده مىشود.

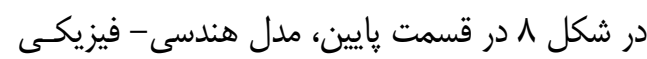
و در قسمت بالا پاسخ GPR بخشهايى از استخوان بـدن

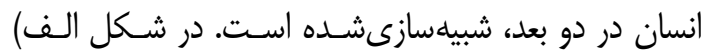

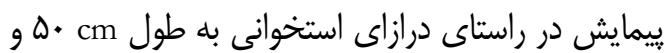

موفقيت در اين زمينهها مورداسـتفاده قراركرفتـهـ اســــ

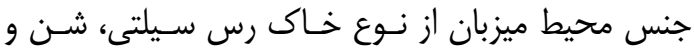
ماسه خشك يا خاك ماسهاى انتخابشده است. بلهنظور اجتناب از يراكندگى عددى (دكرنـامى مكـانى)، فواصـل

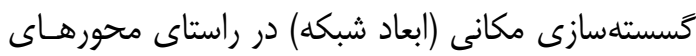

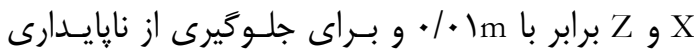

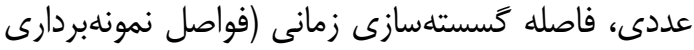

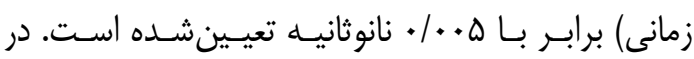

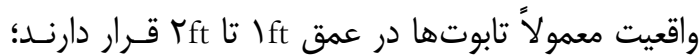

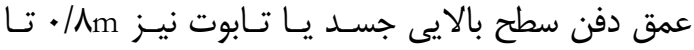

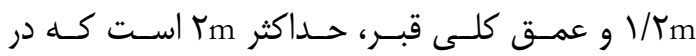
مدلسازىها نيز اين مقادير منظور شده است.

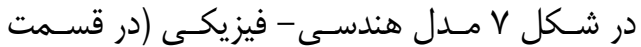

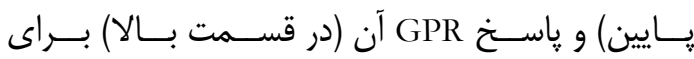

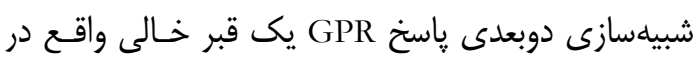

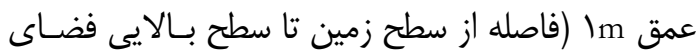
خالى) در دو حالت الف) ييمايش در راستاى امتداد طولى (اسلى

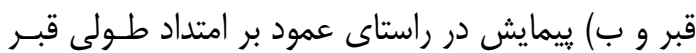

جدول r: برخى از ويزگى هاى الكتريكى مواد موردمطالعه [41-39]

Table 2: Some of the electrical properties of studied materials [39-41]

\begin{tabular}{|c|c|c|c|}
\hline $\begin{array}{c}\text { (m/ns) EM سرعت موج } \\
\text { Velocity of EM wave (m/ns) }\end{array}$ & $\begin{array}{l}\text { هدايت الكتريكى (ms/m) } \\
\text { Conductivity (mS/m) }\end{array}$ & $\begin{array}{c}\text { كذردهى دىالكتريك نسبى } \\
\text { Relative dielectric permittivity }\end{array}$ & $\begin{array}{c}\text { ماده (محيط) } \\
\text { Material (medium) }\end{array}$ \\
\hline 0.12 & 6.67 & 6 & خاى رس سيلتى \\
\hline \multirow[t]{2}{*}{0.3} & 0 & 1 & $\begin{array}{l}\text { هو } \\
\text { Air }\end{array}$ \\
\hline & 1.4 & 10 & $\begin{array}{l}\text { خاك ماسهاى معمولى } \\
\text { Ordinary sandy soil }\end{array}$ \\
\hline 0.15 & 0.05 & 4 & $\begin{array}{c}\text { شن و ماسه خشك } \\
\text { Dry sand and gravel }\end{array}$ \\
\hline 0.07 & 10 & 19 & $\begin{array}{c}\text { شن و ماسه مرطوب } \\
\text { Wet sand and gravel }\end{array}$ \\
\hline \multirow[t]{5}{*}{0.017} & $10^{4}-10^{7}$ & $100-300$ & $\begin{array}{c}\text { فلز } \\
\text { Metal } \\
\end{array}$ \\
\hline & $0.33 * 10^{-12}$ & 2.3 & $\begin{array}{l}\text { جوب خشك } \\
\text { Dry wood }\end{array}$ \\
\hline & 0.14 & 2.6 & خاى ماسهاى خشك \\
\hline & 6.9 & 25 & خاك ماسهاى مرطوب \\
\hline & 0.7 & 23 & $\begin{array}{c}\text { استخوان بدن انسان } \\
\text { Bone of the human body }\end{array}$ \\
\hline
\end{tabular}

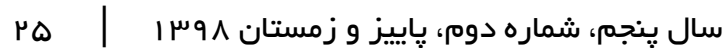



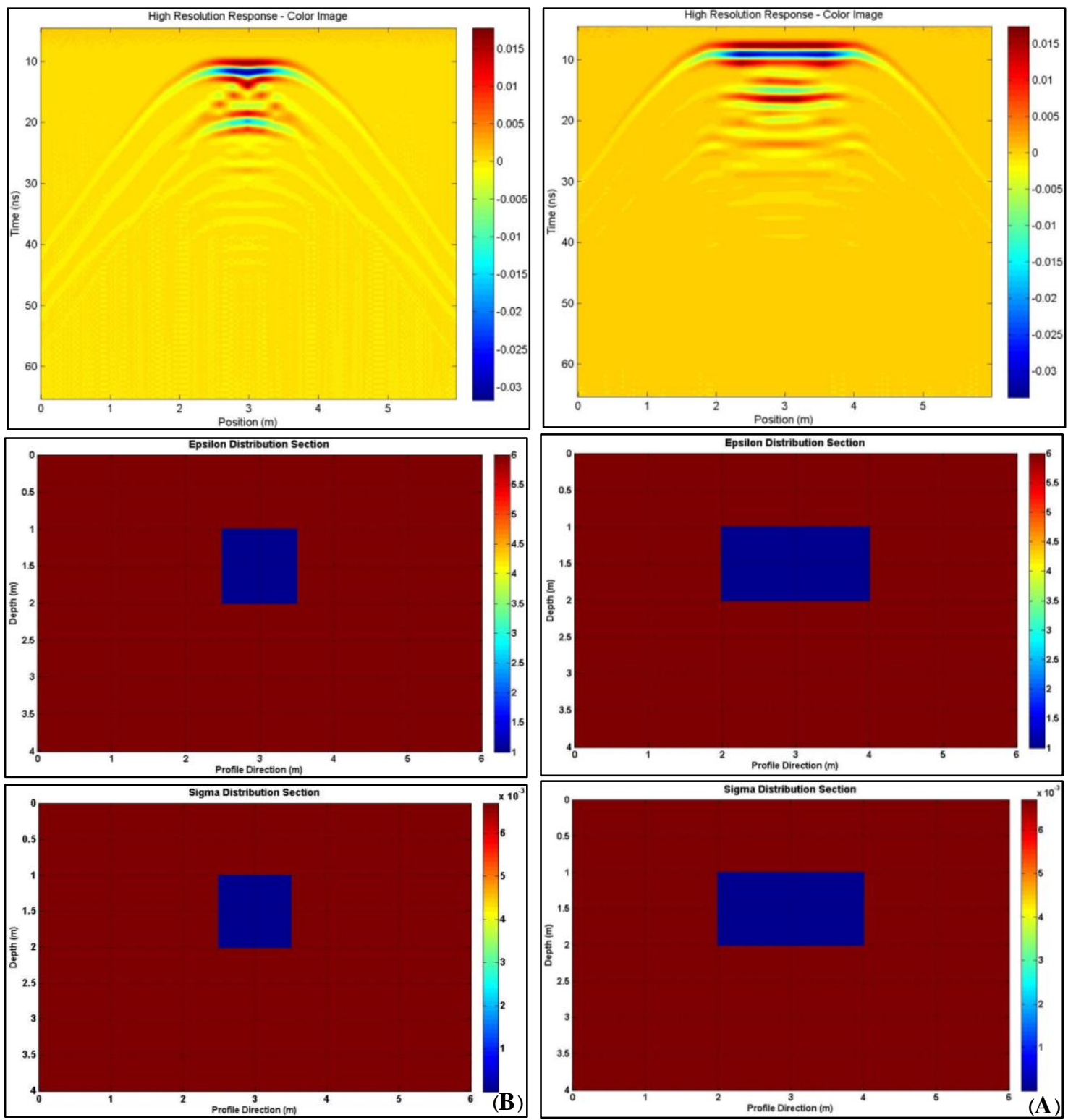

شكل V: مدل هندسى - فيزيكى (رديف وسط، كذردهى دى الكتريك و رديف بإيين، هدايت الكتريكى) و واسخ GPR آن (در قسمت بالا) براى

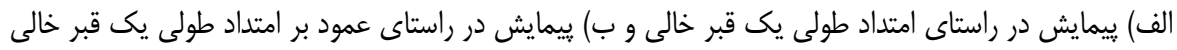

Fig. 7: Geometrical-physical model (middle and bottom rows indicate dielectric permittivity and electrical conductivity, respectively) and its GPR response (at the top) for A) traverse along the longitude of an empty grave, B) traverse along perpendicular the longitude of an empty grave

با توجه به اين شكل مىتوان كَت كه بـهـور كلى

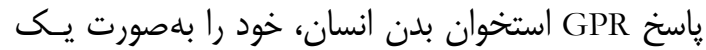
بازتاب هذلولى شكل نشان مى دهد. در مـورد اسـتخوان قسمتهاى مختلف بدن انسان (بلجز استخوان جمجمـهـ

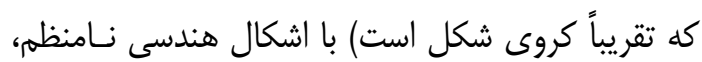

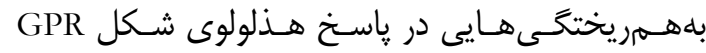
مشاهده مى شود و براى استخوانهاى كشـيده و طويـل،
عرض cm واقع در عمق دفن يك متر (فاصله از سطح

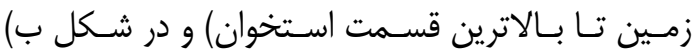

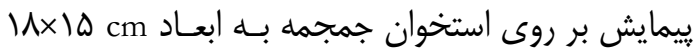
واقع در عمق دفن •م سانتىمترى (فاصله از سطح زمين تا بالاترين قسمت استخوان) صورت كرفته است. در اين

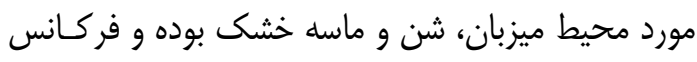

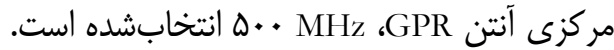



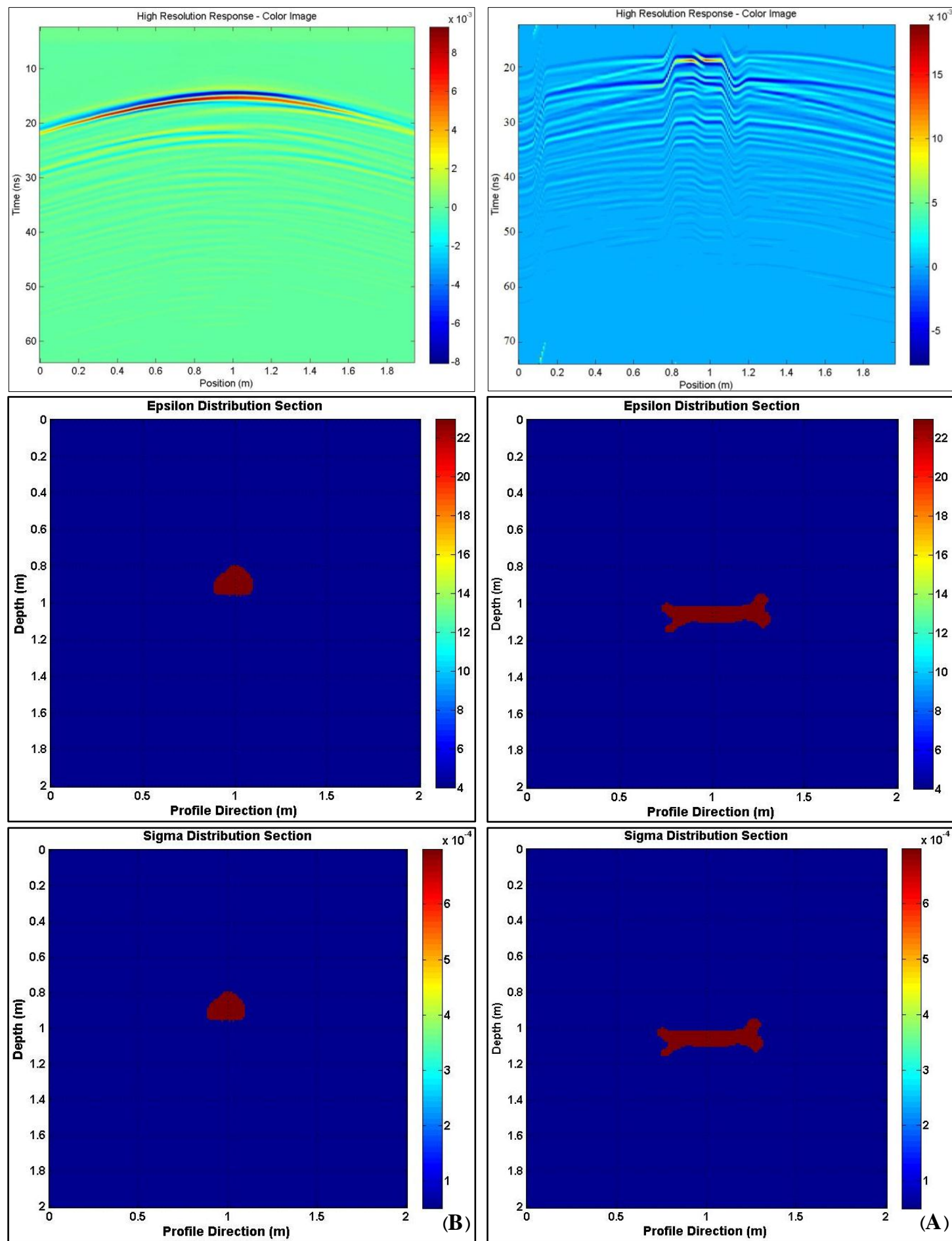

شكل م: مدل هندسى - فيزيكى (رديف وسط، كذردهى دىالكتريك و رديف هايين، هدايت الكتريكى) و پاسخ GPR آن (در قسمت بالا) براى

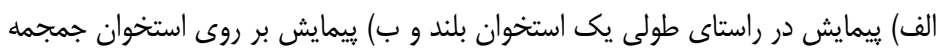

Fig. 8: Geometrical-physical model (middle and bottom rows indicate dielectric permittivity and electrical conductivity, respectively) and its GPR response (at the top) for A) traverse along the longitude of the long bone, B) traverse on the skull bone

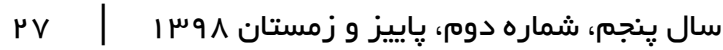




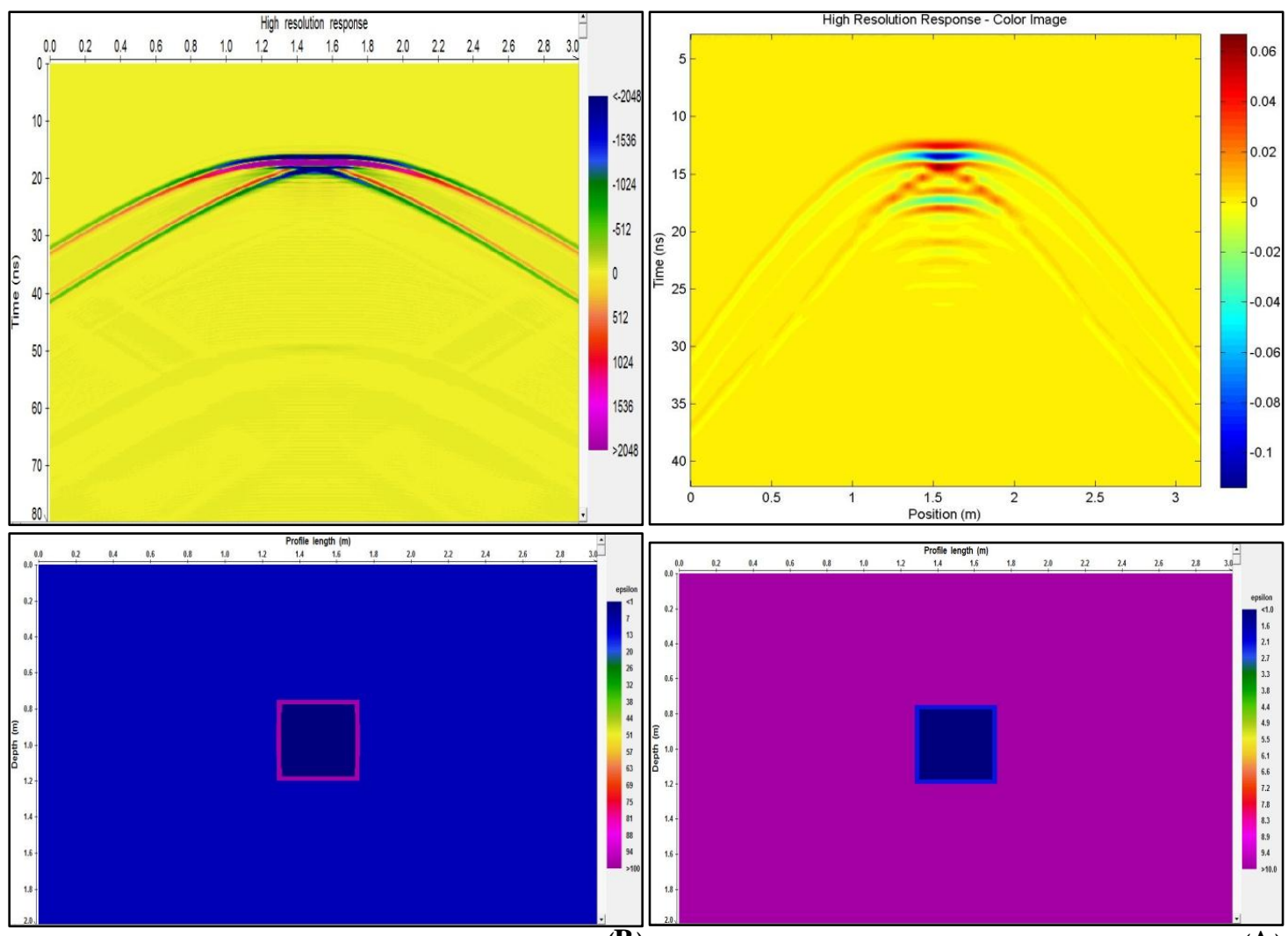

(B)

(A)

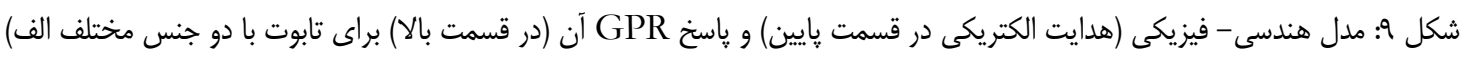

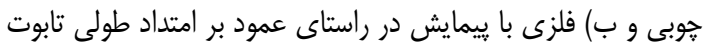

Fig. 9: Geometrical-physical model (electrical conductivity at the bottom) and its GPR response (at the top) for a coffin with 2 different material types A) wooden, B) metallic by traverse along perpendicular the longitude of the coffin

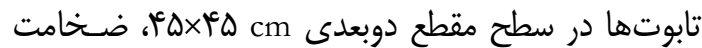

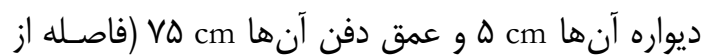

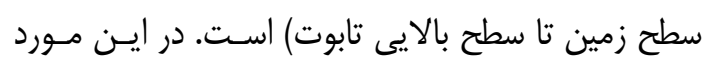

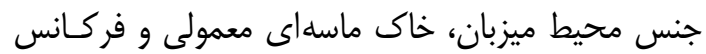

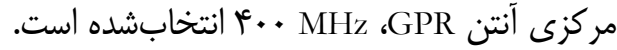

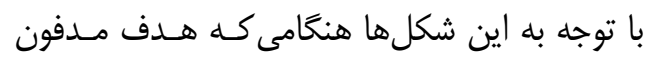
داراى شكل هندسى مانند يك تابوت خوبى بوده و با هوا

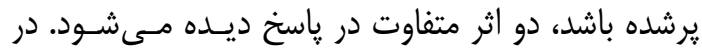
اين مورد ياسخ سقف تابوت در حدود با با نانوثانيسه و اثـر كف تابوت در حدود IV نانوثانيه بهوضوح مشخص بـات بـوده

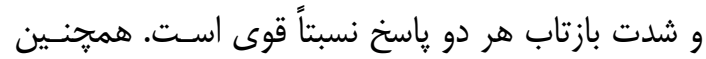

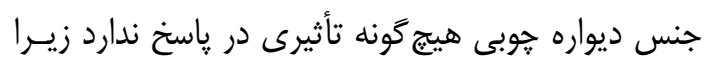
از يكسو ضخامت ديواره هوبى در مقايسه با ابعاد تـابوت

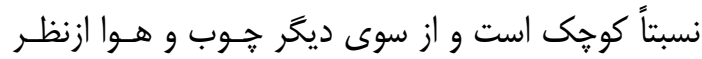

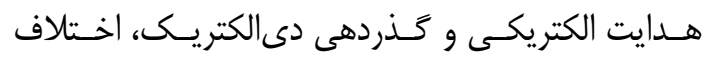

كاهى هذلولوى بلهقدى يهمن و هموار مىشود كه شـبيه

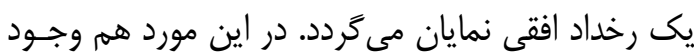

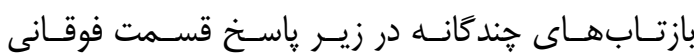

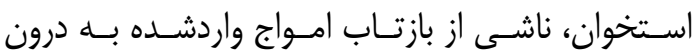

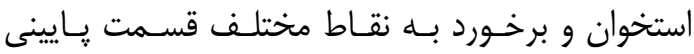

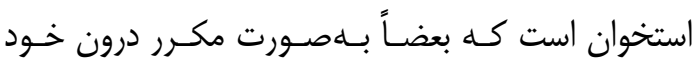
استخوان صورت مى خيرد.

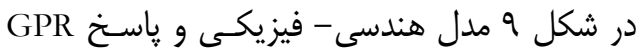

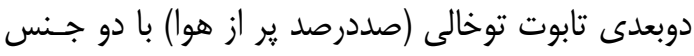

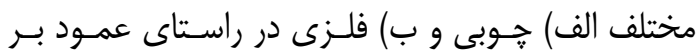

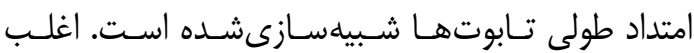

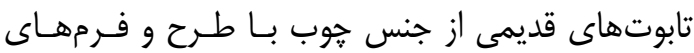

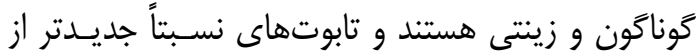

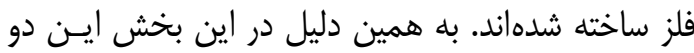

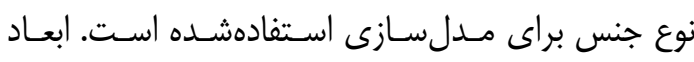

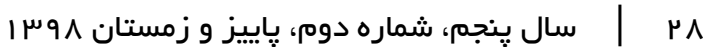


انجام كرفته كه توالى مراحـل يردازشـى شـامل تصـحيح ساكن (Static correction)، بردارنده ميانكين Subtract)

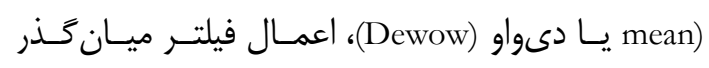
(Background بردارنسـ (Band pass filter) و و برانبارش (Stackingoval)

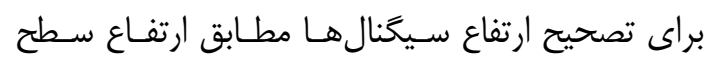

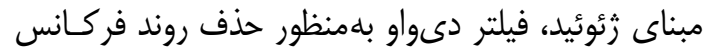

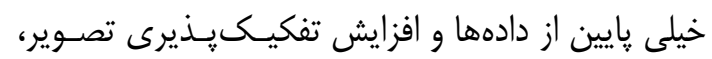

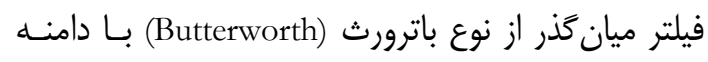

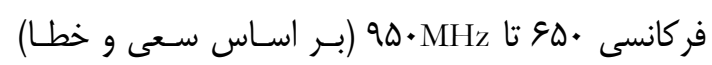

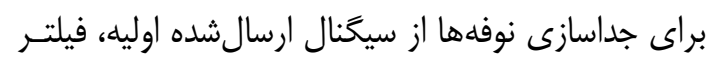

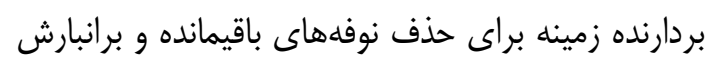

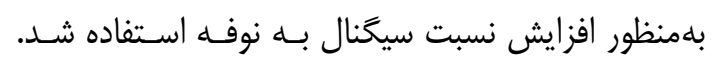

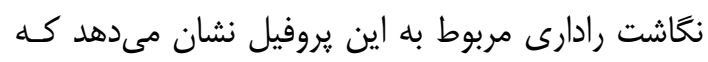

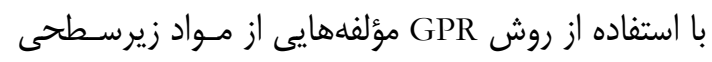

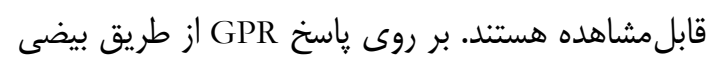

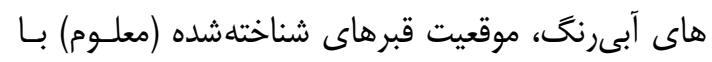
شدت بازتابهاى قوى بلوضوح قابلمشاهده است كه با فيا

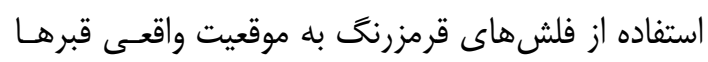

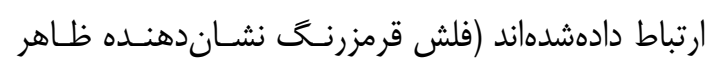
شدن جسد در نغاشت رادارى است).

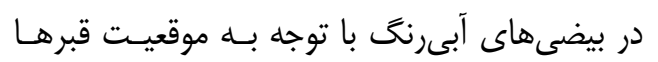

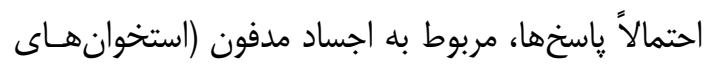

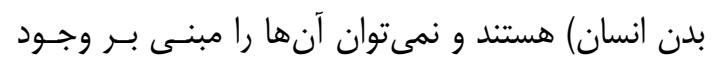

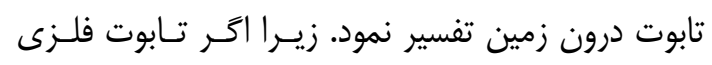

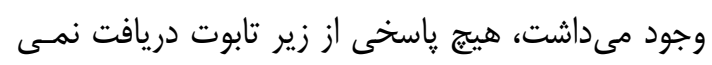

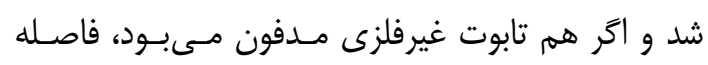

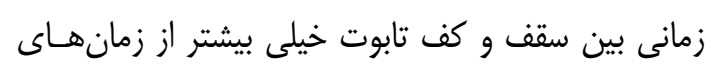

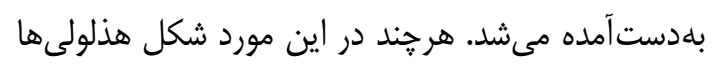

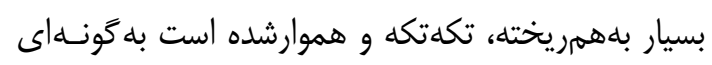

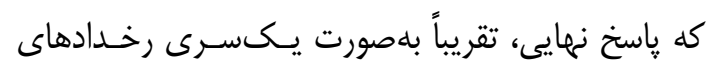

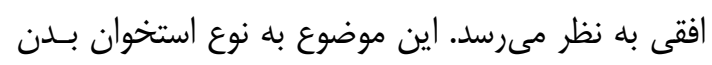

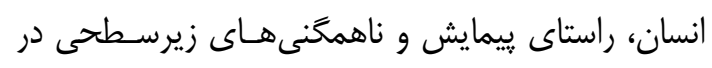

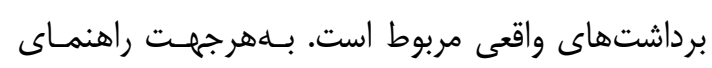

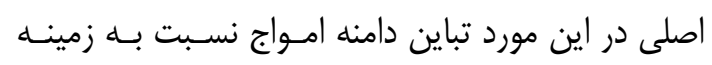

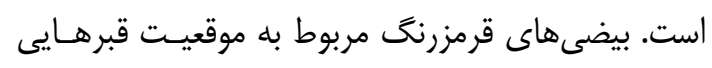

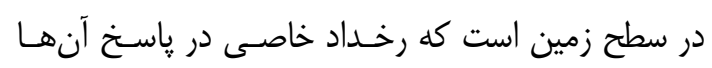

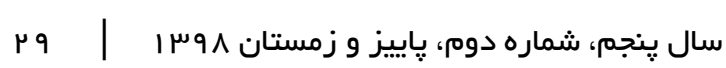

هندانى ندارند. اثراتى هم كه در زير پِاسـخ كـف تـابوت

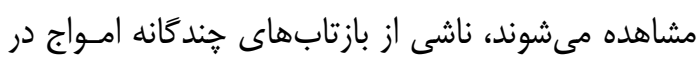

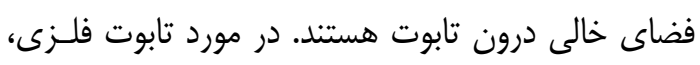

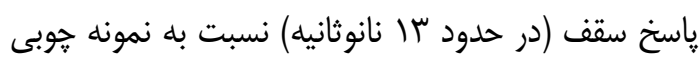

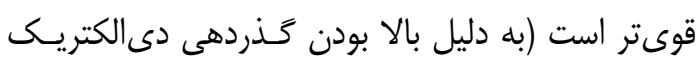

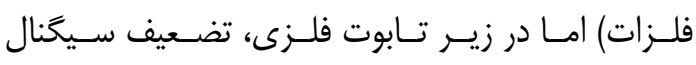

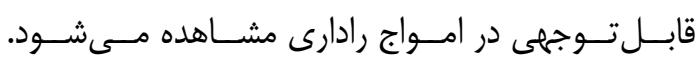

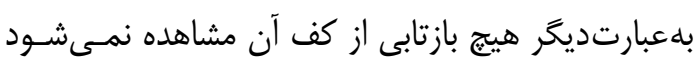

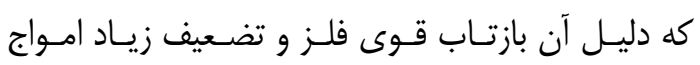

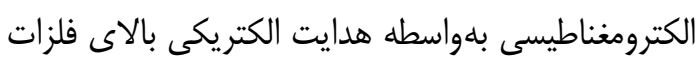
است. اخر هم در مدل سازى به هر دليلى (مـثلاً در نظـر

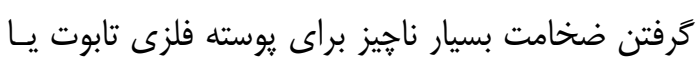

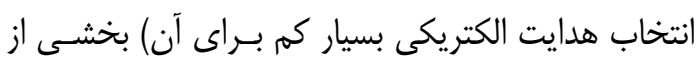

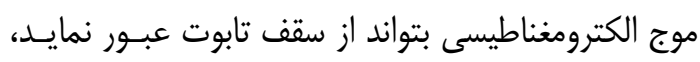
به خاطر كم بودن فاصله بين سقف و كف تـابوت و نيـز

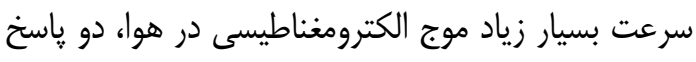
سقف و كف با يكديخر تر كيب مىشوند و داد درنتيجه ياسخ واضحى از كف تابوت قابل مشاهده نيست و ايـن نشـانه

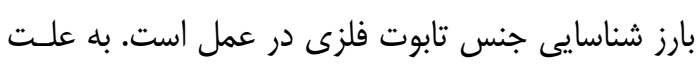

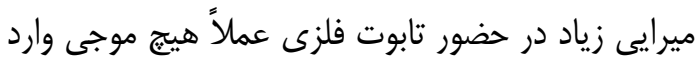
آن نشده و حتى اخر داخل تابوت فلزى اسـتخوان سـالم

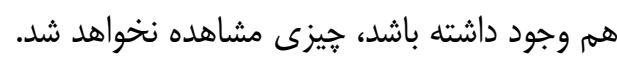

\section{ع-0. بررسى ياسخ دادههاى واقعى GPR}

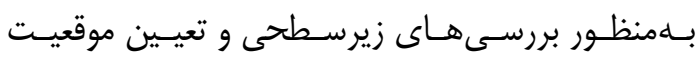
قبرهاى ناشناخته در يك قبرستان نسبتاً قديمى، عمليات

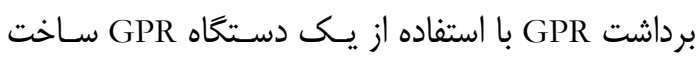

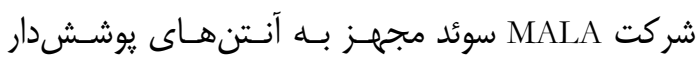
(Shielded) شد. بلهنوان نمونه در شـكل • ا شـيوه انجـام عمليـات

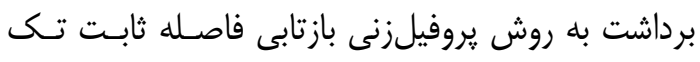

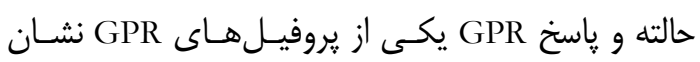

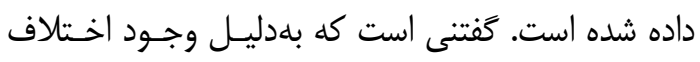

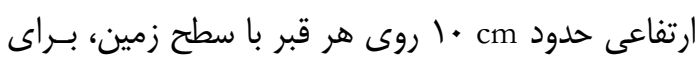

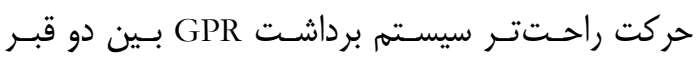

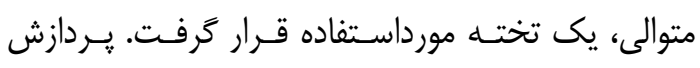

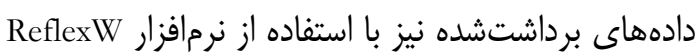




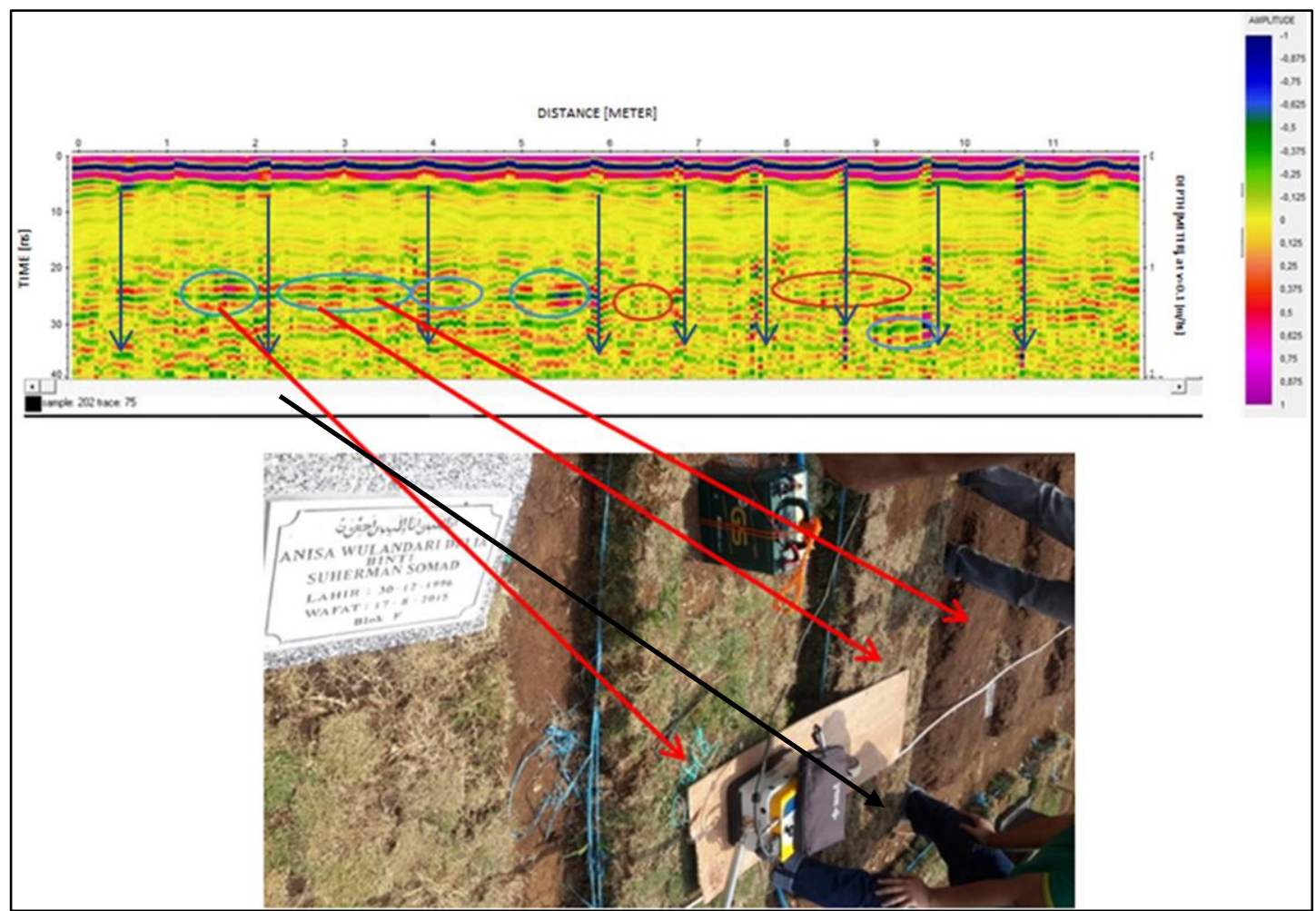

شكل • ا: برداشت دادههاى GPR بر روى يك قبرستان قديمى

Fig. 10: GPR data acquisition on the ancient cemetery

آشكارسازى و تشـخيص موقعيـت قبرهـاى نامشـخص و

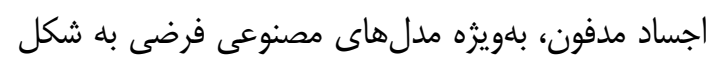

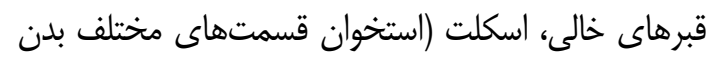

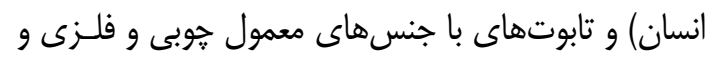

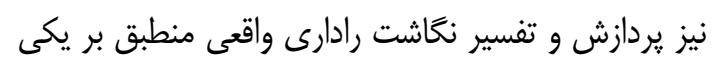

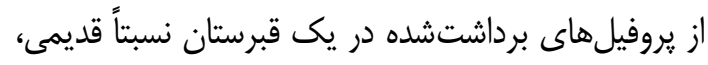

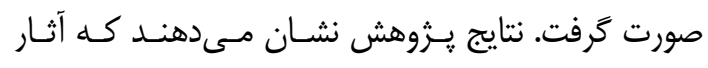

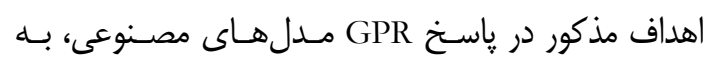

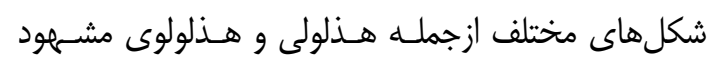

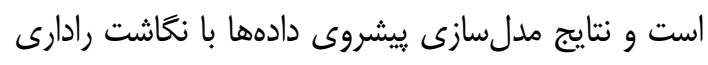

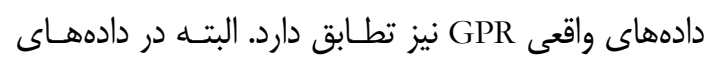

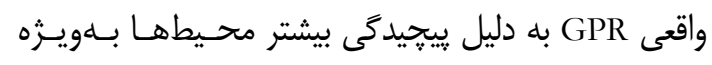

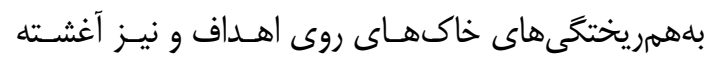

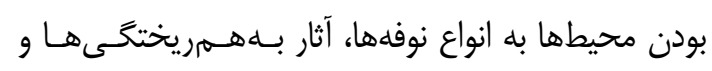

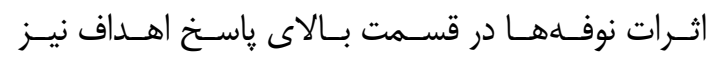
قابلمشاهده هستند.

بلهور كلى بر اساس نتايج ايـن يـروهش مسىتـوان

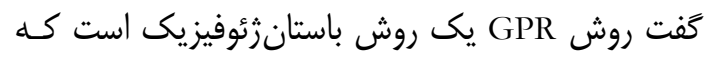

مشهود نيست؛ بهعبارتديخر تباين دامنه هندانى بين

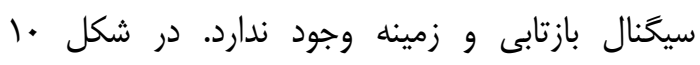

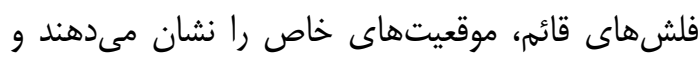

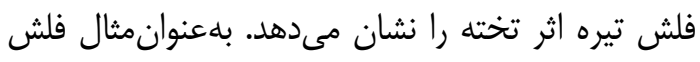

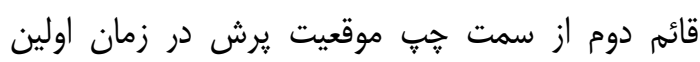

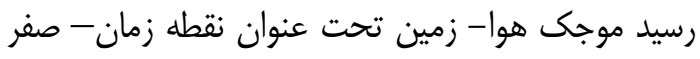

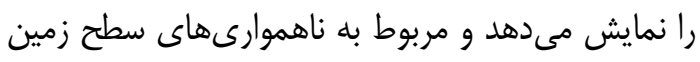

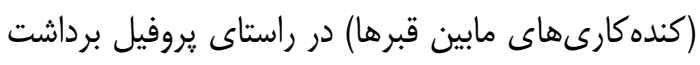

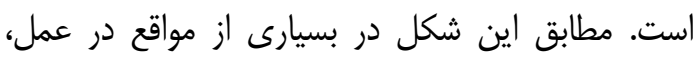

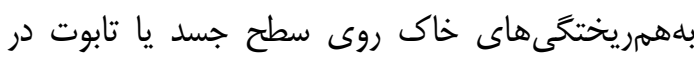
ياسخ امواج GPR بلوضوح قابلمشاهده است.

\section{0. نتيجه كيرى}

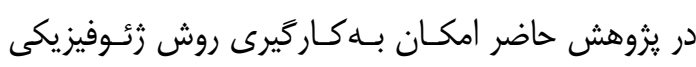

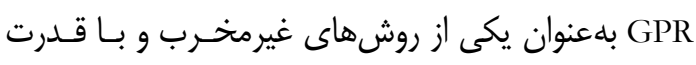

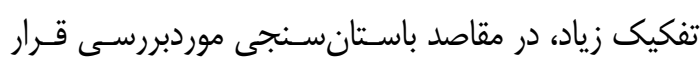

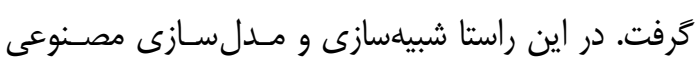
ييشروى دادههاى GPR متناظر با اهداف متداول در زمينه

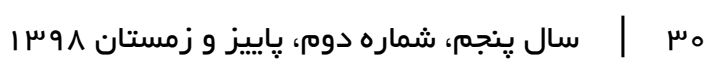




$$
\begin{aligned}
& \text { نامشخص، تابوتهاى با جنسهـاى گونـاگون و اجسـاد } \\
& \text { مدفون در زير زمين را دارا است. }
\end{aligned}
$$

\section{References}

[1] Annan AP. Ground penetrating radar workshop notes. Sensors \& Software Inc., Ontario, Canada. 2001.

[2] Knödel K, Lange G, Voigt HJ. Environmental geology: handbook of field methods and case studies. Springer Science \& Business Media; 2007 Dec 31.

[3] Ali Tajer S, Afshari Azad S. Investigating the role of geomatics engineering in the applications of cultural heritage, archeology and architecture. Pazhoheshha-ye Bastanshenasi Iran. 2014; 3(5):169195. [in Persian]

$$
\begin{aligned}
& \text { [عليتاجر سـعيد، افشـارى آزاد سـميه. بررسـى جايخـاه }
\end{aligned}
$$

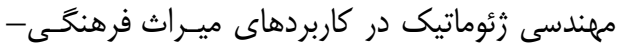

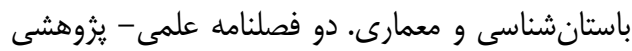

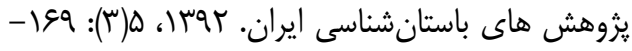

$$
\begin{aligned}
& \text { [190 }
\end{aligned}
$$

[4] Sleep NH, Fujita K. Principles of geophysics. Malden, Massachusetts: Blackwell Science; 1997.

[5] Vickers R, Dolphin L, Johnson D. Archeological investigations at chaco canyon using a subsurface radar.

[6] Fischer PM, Follin SG, Ulriksen P. Subsurface Interface Radar Survey at Hala Sultan Tekke, Cyprus. Swedish Annual Studies in Mediterranean Archaeology. 1980;63:48-64.

[7] Sheets PD, Loker WM, Spetzler HA, Ware RW. Geophysical exploration for ancient Maya housing at Ceren, El Salvador. National Geographic Research Reports. 1985;20:645-56.

[8] Conyers LB, Goodman D. Groundpenetrating radar. An Introduction for Archaeologist: AltaMira Press; 1997 Mar.

[9] Martino L, Bonomo N, Lascano E, Osella A, Ratto N. Electrical and GPR prospecting at Palo Blanco archaeological site, northwestern Argentina. Geophysics. 2006 Nov;71(6):B193-9.

[doi.org/10.1190/1.2345193]
قابليـت كـاربرد در زمينــه مطالعـات باسـتانشناسـى در

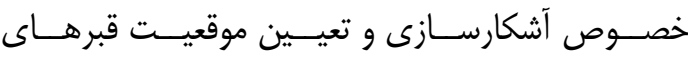

[10] Arciniega-Ceballos A, HernandezQuintero E, Cabral-Cano E, MorettAlatorre L, Diaz-Molina O, SolerArechalde A, Chavez-Segura R. Shallow geophysical survey at the archaeological site of San Miguel Tocuila, Basin of Mexico. Journal of Archaeological Science. 2009 Jun 1;36(6):1199-205. [doi.org/10.1016/j.jas.2009.01.025]

[11 Goodman D, Piro S, Nishimura Y, Schneider K, Hongo $\mathrm{H}$, Higashi $\mathrm{N}$, Steinberg J, Damiata B. GPR archaeometry. Ground Penetrating Radar Theory and Applications. 2008 Dec 8:479-508.[ doi.org/10.1016/B978-0-44453348-7.00015-6]

[12] Sambuelli L, Calzoni C, Stocco S, Rege R. Geophysical measurements on the occasion of the moving of an ancient Egyptian sculpture. InProc. GNGTS Conf.(Trieste, Italy, 16-19 November) 2010 Nov (pp. 595-9).

[13] Solla M, Lorenzo H, Novo A, Riveiro B. Evaluation of ancient structures by GPR (ground penetrating radar): the arch bridges of Galicia (Spain). Scientific Research and Essays. 2011 Apr 18;6(8):1877-84.

[14] Shyeh SK, Nordiana MM, Anuar S, Saad R, Saidin M. Archaeological Evidences Detection by using GPR Method: SB2K Site. EJGE, Bund. Y. 2014;19:8569-78.

[15] Aydin A, Baykan O, Akyol E. Detecting ancient water distribution system using GPR in Patara, Antalya, Turkey. Multidisciplinary Engineering Science and Technology (JMEST). 2014;1(5):32-8.

[16] Ahmadpour A, Kamkar Rouhani A, Ahmadi R. Archaeological exploration of Tappeh Hissar, Damghan using forward and inverse modeling of GroundPenetrating Radar data. Journal of Research on Archaeometry. 2016 Sep 10;2(1):1-6. [doi.org/10.29252/jra.2.1.1] 
[17] Mellett JS. Location of human remains with ground-penetrating radar. InFourth International Conference on Ground Penetrating Radar 1992 Jun 8 (pp. cp-303). European Association of Geoscientists \& Engineers. [doi.org/10.3997/2214-4609pdb.303.45]

[18] Patch, Sh., (2009), Identification of unmarked graves at B.F. Randolph cemetery using Ground Penetrating Radar (GPR), Report submitted to Historic Columbia Foundation.

[19] Barone PM, Swanger KJ, Stanley-Price N, Thursfield A. Finding graves in a cemetery: preliminary forensic GPR investigations in the non-Catholic cemetery in Rome (Italy). Measurement. 2016 Feb 1;80:53-7. [doi.org/10.1016/j.measurement.2015.11. 023]

[20] Fernández-Álvarez JP, Rubio-Melendi D, Martínez-Velasco A, Pringle JK, Aguilera HD. Discovery of a mass grave from the Spanish Civil War using Ground Penetrating Radar and forensic archaeology. Forensic Science International. 2016 Oct 1;267:e10-7. [doi.org/10.1016/j.forsciint.2016.05.040]

[21] Widodo W, Aditama IF, Syaifullah K, Mahya MJ, Hidayat M. Detecting buried human bodies using ground-penetrating radar. Earth Science Research. 2016;5(2):59.

[doi.org/10.5539/esr.v5n2p59]

[22] Amari IE, Alsulaimani GS. Detecting and Imaging Historical Graves by Using Visual Inspection and Ground Penetrating Radar Investigation.

[23] Oveisi-Moakhar M, Ghasemi V, ShahNazari, H. Magnetic and radar studies on the arches of Khosrow historical structure in Ghasr-e-Shirin city. 12th Geophysics Conference of Iran, 2005. [in Persian]

[اويسـى مـوخر محسـن، قاسـمى وحيـد، شـاه نظــى

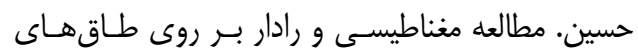

عمـارت تــاريخى خســرو در شـهمر قصــر شــيرين.

$$
\text { دوازدهمين كنفرانس زئوفيزيك ايران، عربا]. }
$$

[24] Reshmeh-Karim A, Kamkar-Rouhani A, Arab-Amiri A. Application of GroundPenetrating Radar (GPR) method in archaeology investigations, case study: Damghan Tappeh-Hissar. 15 Symposium of Geological Society of Iran, 2001. [in Persian]

] رشمه كريم ارزنخ، كامكار روحـانى ابوالقاسـه، عـرب .

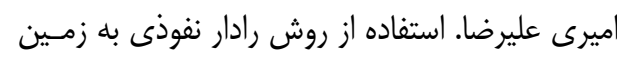
در كاوشهاى باستانشناسى، مطالعه مـوردى (GPR)

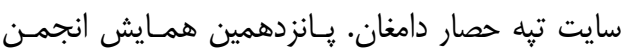

زمينشناسى ايران، •وسار].

[25] Mohammad khani K. Application of exploration geophysics methods in archaeology (archaeogeophysics), case study: study of magnetometry in Takht-eJamshid and Pasargad, MSc. Thesis on archaeology, Tarbiat Modares University 2004. [in Persian]

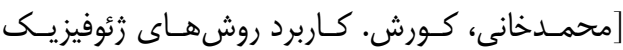
اكتشافى در باستانشناسـى (آركئوزئوفيزيـك)، مطالعـهـ

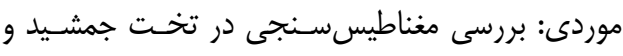

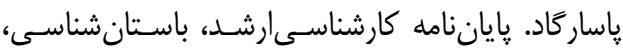

دانشعاه تربيت مدرس سمرسار.

[26]http://jamejamonline.ir/online/28533781 12472890822/

[27]http://elmi.akaup.com/elmi/chemistry1/ news20177822331357613.html

[28] Golalipour M.J, Jahanshahi M, Haydari K, Rezaee N. Estimation of cranial capacity of Turkman's 17-20 years old in GorganNorth of Iran 2005, 7(1): 31-33. [in Persian]

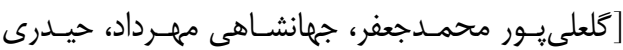

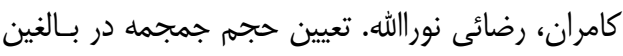
.

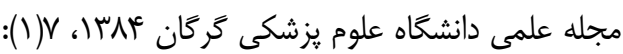

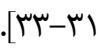

[29]https://en.wikipedia.org/wiki/List_of_bo nes_of_the_human_skeleton\#Spine_(ver tebral_column)

[30] Annan AP. GPR-History, trends, and future developments. Subsurface sensing technologies and applications. 2002 Oct 1;3(4):253-70.

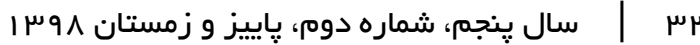


[doi.org/10.1023/A:1020657129590]

[31] https://www.impulseradar.se/technology

[32] tagrsi.com/examples/. Sturm Inc., TAG research, Technical. Archaeological. Geophysical. Solutions.

[33] www.google.com/search?q=gpr+images

[34] Jol HM, editor. Ground penetrating radar theory and applications. elsevier; 2008 Dec 8.

[35] Annan AP. GPR methods for hydrogeological studies. In Hydrogeophysics 2005 (pp. 185-213). Springer, Dordrecht. [doi.org/10.1007/14020-3102-5_7]

[36] Sadiku MN. Numerical techniques in electromagnetics. CRC press; 2000 Jul 12. [doi.org/10.1201/9781420058277]

[37] Irving J, Knight R. Numerical modeling of ground-penetrating radar in 2-D using MATLAB. Computers \& Geosciences. $2006 \quad$ Nov 1;32(9):1247-58. [doi.org/10.1016/j.cageo.2005.11.006]

[38] Ahmadi R, Fathianpour N, Norouzi G.H. Improving Ground-Penetrating Radar (GPR) forward modeling approach using the numerical finite difference method, Iranian Journal of Geophysics 2014, 8(3): 114-130. [in Persian]

[احمدى رضا، فتحيانيور نـادر، نـوروزى غلامحســين.

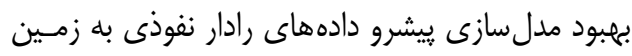

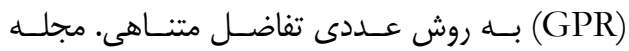

زئوفيزيك ايران سوسا، ג|r):

[39] Davis JL, ANNAN AP. Groundpenetrating radar for high-resolution mapping of soil and rock stratigraphy 1. Geophysical prospecting. 1989 Jul;37(5):531-51. doi.org/10.1111/j.13652478.1989.tb02221.x]

[40] Zeng X, McMechan GA. GPR characterization of buried tanks and pipes. Geophysics. 1997 May;62(3):797806. [doi.org/10.1190/1.1444189]

[41] Ahmadi R, Fathianpour N, Norouzi GH. Detecting physical and geometrical parameters of some common geotechnical targets through their effects on GPR responses. Arabian Journal of Geosciences. 2015 Jul 1;8(7):4843-54. [doi.org/10.1007/s12517-014-1517-5]

[42] Ahmadi R. Developing an intelligent algorithm to detect geometrical and physical parameters of geotechnical targets using GPR responses. Ph.D thesis, Mining engineering department, College of engineering, University of Tehran. 2015. [in Persian].

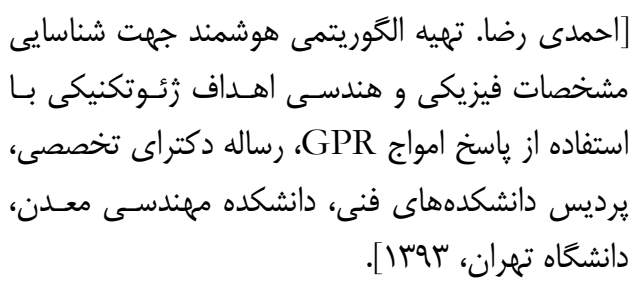

